\title{
Distribution of indole-3-acetic acid in Petunia hybrida shoot tip cuttings and relationship between auxin transport, carbohydrate metabolism and adventitious root formation
}

\author{
Amir H. Ahkami • Michael Melzer • Mohammad R. Ghaffari • \\ Stephan Pollmann • Majid Ghorbani Javid • Fahimeh Shahinnia • \\ Mohammad R. Hajirezaei • Uwe Druege
}

Received: 5 December 2012/ Accepted: 28 May 2013/Published online: 14 June 2013

(C) The Author(s) 2013. This article is published with open access at Springerlink.com

\begin{abstract}
To determine the contribution of polar auxin transport (PAT) to auxin accumulation and to adventitious root (AR) formation in the stem base of Petunia hybrida shoot tip cuttings, the level of indole-3-acetic acid (IAA) was monitored in non-treated cuttings and cuttings treated with the auxin transport blocker naphthylphthalamic acid (NPA) and was complemented with precise anatomical studies. The temporal course of carbohydrates, amino acids and activities of controlling enzymes was also investigated. Analysis of initial spatial IAA distribution in the cuttings revealed that approximately 40 and $10 \%$ of the total IAA pool was present in the leaves and the stem base as rooting zone, respectively. A negative correlation existed between leaf size and IAA concentration. After
\end{abstract}

M. R. Hajirezaei and U. Druege have contributed equally to the work.

Electronic supplementary material The online version of this article (doi:10.1007/s00425-013-1907-z) contains supplementary material, which is available to authorized users.

A. H. Ahkami

Institute of Biological Chemistry (IBC), Washington State

University, Pullman, WA 99164-6340, USA

M. Melzer · M. R. Ghaffari · M. R. Hajirezaei ( $\bowtie)$ Leibniz Institute of Plant Genetics and Crop Plant Research (IPK), Corrensstr. 3, Gatersleben, 06466 Seeland, Germany e-mail: mohammad@ipk-gatersleben.de

S. Pollmann

Parque Científico y Tecnológico de la U.P.M, Centro de Biotecnología y Genómica de Plantas U.P.M.-I.N.I.A, Campus de Montegancedo, Pozuelo de Alarcón, 28223 Madrid, Spain

M. Ghorbani Javid

Department of Agronomy and Plant Breeding Sciences,

College of Abureihan, University of Tehran, Tehran, Iran excision of cuttings, IAA showed an early increase in the stem base with two peaks at 2 and $24 \mathrm{~h}$ post excision and, thereafter, a decline to low levels. This was mirrored by the expression pattern of the auxin-responsive $G H 3$ gene. NPA treatment completely suppressed the 24-h peak of IAA and severely inhibited root formation. It also reduced activities of cell wall and vacuolar invertases in the early phase of AR formation and inhibited the rise of activities of glucose-6-phosphate dehydrogenase and phosphofructokinase during later stages. We propose a model in which spontaneous AR formation in Petunia cuttings is dependent on PAT and on the resulting 24-h peak of IAA in the rooting zone, where it induces early cellular events and also stimulates sink establishment. Subsequent root development stimulates glycolysis and the pentose phosphate pathway.

Keywords Polar auxin transport (PAT) - IAA · GH3 • Sink establishment $\cdot$ Petunia $\cdot$ Root development

\footnotetext{
F. Shahinnia

Australian Centre for Plant Functional Genomics,

University of Adelaide, Waite Campus, Hartley Grove Urrbrae,

Adelaide 5064, Australia

U. Druege $(\bowtie)$

Leibniz Institute of Vegetable and Ornamental Crops

Großbeeren/Erfurt e.V. (IGZ), Kuehnhaeuser Str. 101,

99090 Erfurt, Germany

e-mail: druege@erfurt.igzev.de
} 


$\begin{array}{ll}\text { Abbreviations } \\ \text { AR } & \text { Adventitious root } \\ \text { AUX } & \text { Auxin permease } \\ \text { CDK } & \text { Cyclin-dependent kinase } \\ \text { FW } & \text { Fresh weight } \\ \text { GC-MS/MS } & \begin{array}{l}\text { Gas chromatography-tandem mass } \\ \text { spectrometry }\end{array} \\ \text { GH3 } & \text { Gretchen Hagen 3 } \\ \text { Glc6PDH } & \text { Glucose-6-phosphate dehydrogenase } \\ \text { Hpe } & \text { Hours post excision } \\ \text { IAA } & \text { Indole-3-acetic acid } \\ \text { IAAasp } & \text { Indole-3-acetylaspartic acid } \\ \text { LAX } & \text { Like AUX } \\ \text { MDR } & \text { Multidrug resistance } \\ \text { PGP } & \text { P-glycoprotein } \\ \text { NPA } & \text { Naphthylphthalamic acid } \\ \text { PAT } & \text { Polar auxin transport } \\ \text { PFK } & \text { Phosphofructokinase } \\ \text { PIN } & \text { Pin-formed } \\ \text { PRP } & \text { Proline-rich protein } \\ \text { TIBA } & \text { Triiodobenzoic acid } \\ & \end{array}$

\section{Introduction}

When a cutting is removed from a plant under appropriate conditions, it may produce a new root system and finally an entire individual with a balanced root-to-shoot ratio (Lovell and White 1987). These events involve various anatomical, physiological and molecular changes associated with wound responses in addition to those involved in root formation itself. Adventitious rooting can be considered as an interesting process of post-embryonic organogenesis as it describes the development of new root tissues in locations other than the primary root system (Blakesley et al. 1991). In addition, adventitious root (AR) formation in leafy stem cuttings is a crucial physiological process for the propagation of many ornamental plant species. Despite intensive control of environmental factors in the modern propagation industry, high economic losses still occur as a result of insufficient rooting, which is in direct contrast with the increasing demand for fast and synchronous rooting to meet horticultural standards (Druege 2009).

The formation of ARs is a complex process. It involves successive developmental phases requiring different hormonal signals and other endogenous factors, in which auxin plays a pivotal role (Kevers et al. 1997; De Klerk et al. 1999), and is affected by environmental factors, such as wounding or light (Sorin et al. 2005). Auxins, of which indole-3-acetic acid (IAA) constitutes the most important endogenous physiologically active fraction (Kerr and
Bennett 2007), have been shown to be effective inducers of AR initiation (Ludwig-Müller 2009). Since their discovery, they have been frequently used in horticultural practice to stimulate rooting and particularly in plant species that show only weak AR formation without external stimuli (Hartmann et al. 2011).

Considering auxin homeostasis in the rooting zone, it has been concluded from observations on different plant species that high concentrations of free auxin are needed during the induction phase of adventitious rooting, whereas during later stages, high auxin levels obviously have an inhibitory action on differentiation and outgrowth of root primordia (De Klerk et al. 1999). One way to reduce active auxin is degradation via oxidative decarboxylation, which is probably associated with one of the important functions of higher peroxidase activity repeatedly observed after the induction phase (Kevers et al. 1997; Tonon et al. 2001). Another way to reduce the level of active auxin is by conjugation to sugars and amino acids (Woodward and Bartel 2005), which may be indicated by an increased levels of IAA conjugates such as indole-3-acetylaspartic acid (IAAasp) during later stages of AR formation (Nordström and Eliasson 1991; Garcia Gomez et al. 1994). In this respect, auxin-inducible GH3 (Gretchen Hagen 3) genes can play an important role in the control of free auxin levels because specific $G H 3$ s can catalyse conjugation of amino acids to IAA (Staswick et al. 2005; Wang et al. 2007). Because of the presence of auxin-responsive elements in the $G H 3$ s' promoter region, the expression of GH3 genes can be used to monitor auxin activity (Hagen et al. 1991; Wang et al. 2007).

Spontaneous AR formation, which does not rely on auxin application, is observed in leafy stem cuttings of many plant species in response to excision from the donor plant. Basipetal auxin transport is assumed to contribute to this phenomenon (Blakesley 1994; De Klerk et al. 1999). This conception is mainly based on the following observations. Firstly, monitoring of endogenous auxin, particularly of IAA, revealed a transient increase in the rooting zone (Blakesley et al. 1991; Blažková et al. 1997; Tonon et al. 2001). Secondly, labelled auxin applied to the apex of cuttings was transported to the stem base (Baadsmand and Andersen 1984; Guerrero et al. 1999). Finally, removal of potential source organs of auxin or application of blockers of polar auxin transport (PAT), such as naphthylphthalamic acid (NPA) or triiodobenzoic acid (TIBA), decreased AR formation (Liu and Reid 1992; Garrido et al. 2002). For example, decapitation and treatment of pea stem cuttings with NPA led to the reduction in IAA levels in cutting bases during the first days after excision, which was associated with lower numbers and shorter lengths of ARs (Nordström and Eliasson 1991; Koukourikou-Petridou and Bangerth 1997). Similarly, application of TIBA to avocado 
cuttings inhibited the differentiation of root primordia and reduced the percentage of rooted cuttings, while the IAA level in the basal stem was only slightly reduced (Garcia Gomez et al. 1994). These studies did not demonstrate a significant increase of IAA in the stem base of non-treated control cuttings, although they did produce a high number of roots. Because a transient increase in the level of IAAasp was detected in the basal part of untreated cuttings, the authors speculated that the initial IAA level could be sufficient to induce ARs or that a steady but non-detected release of IAA from IAAasp possibly contributed to AR formation (Nordström and Eliasson 1991; Garcia Gomez et al. 1994). However, Blakesley et al. (1991) detected a sharp peak of IAA in hypocotyls of Phaseolus aureus already within the first 10 -h post excision. Thus, the first samplings of pea and avocado at $24 \mathrm{~h}$ and 3 days post excision, respectively (Nordström and Eliasson 1991; Koukourikou-Petridou and Bangerth 1997; Garcia Gomez et al. 1994), may have missed the transient IAA peak. Overall, there are only a few studies that combine modifications of auxin transport with early and frequent analysis of the auxin level in the rooting zone and with precise anatomical investigation.

The role of auxin transport and accumulation in the rooting zone is particularly unclear in relation to the response of carbohydrate metabolism, frequently observed during AR formation in cuttings (Ahkami et al. 2009; Druege 2009). Interrelationships between auxin and carbohydrate metabolism during adventitious rooting have been investigated by the application of auxins such as $\alpha$-naphthalene acetic acid and indole-3-butyric acid and monitoring of carbohydrate levels, carbon translocation and activities of some enzymes in the rooting zone. It has been found that auxin application stimulated mobilization of carbohydrates in the upper shoot, increased the translocation of assimilates and increased sugar availability at the site of root primordia development (Altman and Wareing 1975; Haissig 1986; Husen and Pal 2007; Agulló-Antón et al. 2011). Haissig (1974) observed a stimulation of activity of glycerin-aldehyde-3-phosphate dehydrogenase together with enhanced root primordium initiation in the rooting zone of bean hypocotyl cuttings after IAA treatment and suggested that carbohydrate utilization is also subject to auxin. Considering the response of carbohydrate and protein levels in the rooting zone of Tectonia grandis cuttings, Husen and Pal (2007) proposed that auxin contributes to the release of energy and mobilization of proteins, which are necessary for cell division and differentiation. Furthermore, there is increasing evidence that auxin homeostasis and auxin response of root development can be modulated by sugar signalling (Mishra et al. 2009). However, the complex interactions between auxin, overall primary metabolism and cell division during AR formation are far from being elucidated.

Petunia hybrida is an ornamental plant of high economic importance in global horticulture. Over the past two decades, the genus Petunia has served as an excellent model system for uncovering the molecular, biochemical and physiological bases of several plant processes (Underwood et al. 2009). Recently, we established $P$. hybrida as a model species to study molecular and physiological bottle-necks in adventitious rooting of leafy stem cuttings. Focusing on the response of primary metabolism in the rooting zone in relation to anatomical stages, we defined three metabolic phases of AR formation: (1) the sink establishment phase, characterized by apoplastic unloading of sucrose as reflected by induced expression and high activity of cell wall invertase, (2) the recovery phase, characterized by replenishment of resources and (3) the maintenance phase, in which a steady state is maintained via symplastic unloading of sucrose (Ahkami et al. 2009). Ahkami et al. (2009) also observed a fast and transient increase in jasmonic acid in the rooting zone and jasmonates has been shown to stimulate auxin biosynthesis, modulate PAT and interact with auxin signalling (Sun et al. 2009; Hoffmann et al. 2011). However, the role of auxin in AR formation of $P$. hybrida cuttings is still poorly understood. This particularly applies to the contribution of auxin transport and to the interrelationship between auxin and the metabolic response.

The objectives of the present study were as follows: (1) to determine the initial spatial distribution of IAA as an important physiologically active auxin fraction in $P$. hybrida cuttings, (2) to elucidate the relationship between auxin transport, temporal distribution of auxin in the rooting zone and spontaneous development of ARs in $P$. hybrida in response to excision from donor plants and (3) to investigate the possible impact of auxin transport on the primary metabolic responses during AR formation. The spatial and temporal distribution of IAA was analysed in the leaves and stem base of cuttings in non-treated and NPA-treated cuttings using gas chromatography-tandem mass spectroscopy (GC-MS/MS). These experiments were complemented with time course analysis of $G H 3$ expression, of metabolites, of activities of key enzymes and of anatomical changes during AR formation stages.

\section{Materials and methods}

Plant material, growth conditions, NPA treatment and sampling

Leafy stem cuttings of Petunia hybrida cv. Mitchell (original seeds provided from Marcel Buchers lab, ETH 
Zurich, Switzerland) were used for all experiments. Shoot tip cuttings (Fig. 1a) were excised from donor plants and were planted for rooting in plastic trays containing the chemically inert substrate perlite ('Perligran A', particle size 0-6 mm, Knauf Perlite GmbH, Dortmund, Germany). Growth conditions were as described in Ahkami et al. (2009). Foliar spraying of NPA (Duchefa, Haarlem, The Netherlands) was conducted immediately after excision of cuttings to inhibit basal auxin transport in the cuttings. NPA was dissolved in $1 \mathrm{ml} 1 \mathrm{~N} \mathrm{NaOH}$ according to the manufacturer's protocol and diluted with distilled water to a final stock concentration of $100 \mu \mathrm{M}$. Appropriate volumes of stock solution were added to distilled water to obtain the different concentrations required. Five different concentrations of NPA, including 10, 25, 50, 80 and $100 \mu \mathrm{M}$, were tested. Consequently, the concentration of $50 \mu \mathrm{M}$ NPA was used in the following experiments as it caused severe inhibition of rooting without causing wilting of the cuttings.

For analysis of the spatial distribution of IAA, samples of different plant tissues (complete leaves of five different positions, four transversal sections of lowest leaf and three stem sections, as illustrated in Fig. 1a) were immediately transferred into pre-weighed Eppendorf tubes, and the tubes were then re-weighed, immersed in liquid nitrogen and stored at $-80{ }^{\circ} \mathrm{C}$. For analysis of metabolites, enzyme activities and RNA extraction in the rooting zone, stem bases $(0.5 \mathrm{~cm})$ were abscised from non-treated and NPAtreated cuttings [no treatment within $0 \mathrm{~h}$ post excision (hpe)] at 11 time points $(0,2,4,6,12,24,48,72,96,144$, $192 \mathrm{hpe}$ ) during rooting before any roots emerged and then sampled in the same way.

Anatomical investigations and rating of rooting response

For histochemical examination of stem cuttings, 1-mm thick cross-sections were fixed overnight at $4{ }^{\circ} \mathrm{C}$ in $50 \mathrm{mM}$ cacodylate buffer, $\mathrm{pH} 7.2$, containing $2 \%$ (v/v) glutaraldehyde and $2 \%(\mathrm{v} / \mathrm{v})$ formaldehyde, followed by one wash with buffer and two washes with distilled water. For secondary fixation, samples were transferred to a solution of $1 \%(\mathrm{w} / \mathrm{v}) \mathrm{OsO}_{4}$. After $1 \mathrm{~h}$, samples were washed three times with distilled water. Dehydration at $21^{\circ} \mathrm{C}$ was performed stepwise by increasing the concentration of ethanol $(\%, \mathrm{v} / \mathrm{v})$ as follows: $30,40,50,60,75,90 \%$ and $2 \times 100 \%$ ethanol, for $1 \mathrm{~h}$ each. Samples were infiltrated with Lowicryl, LR White (Plano GmbH, Wetzlar, Germany) as follows: (\%, v/v) $25 \%$ overnight, $50 \%$ and $75 \%$ resin in $100 \%$ ethanol for $4 \mathrm{~h}$ each, and then $100 \%$ resin overnight. Samples were transferred into BEEM capsules, incubated there for $3 \mathrm{~h}$ in fresh resin, and polymerized at $60{ }^{\circ} \mathrm{C}$ for $48 \mathrm{~h}$. Semi-thin sections (thickness $3 \mu \mathrm{m}$ ) were
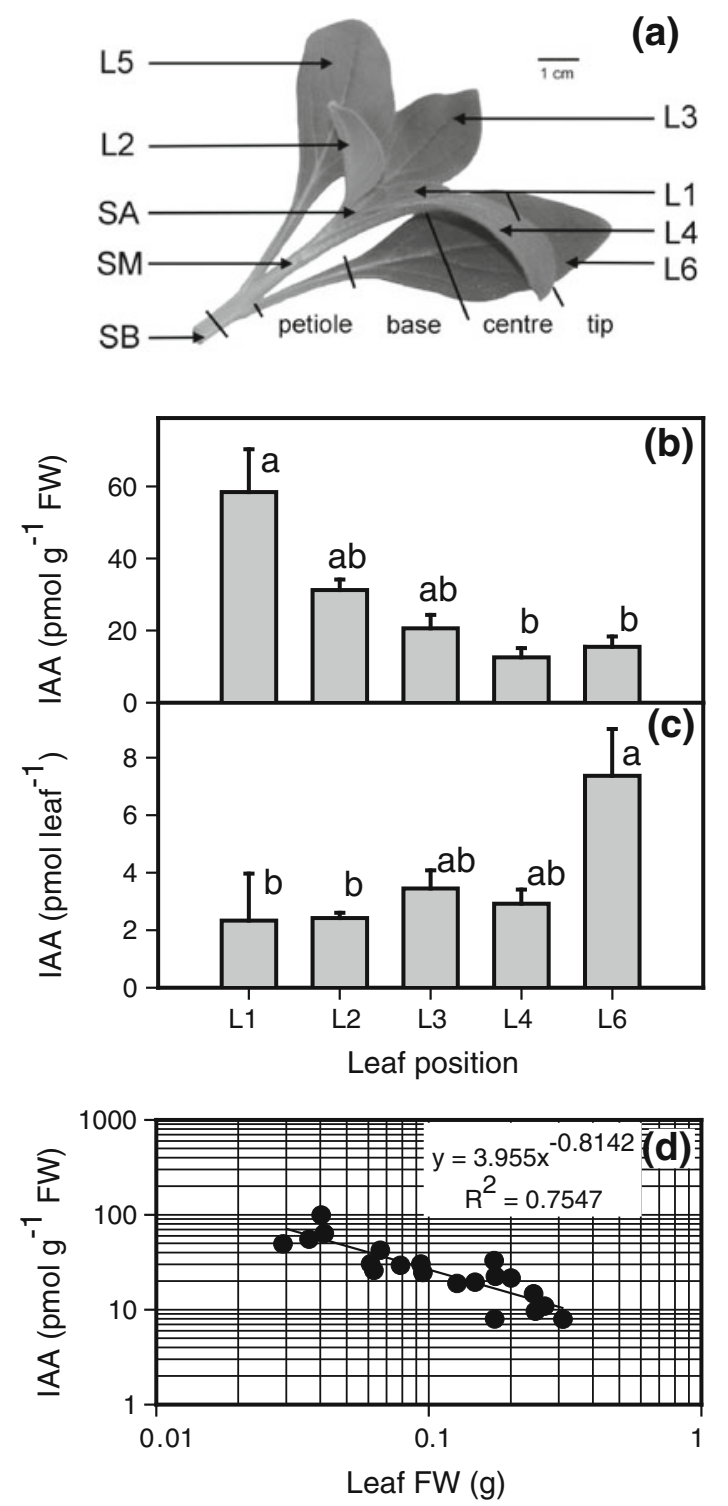

Fig. 1 a Different sections of an excised leafy cutting of $P$. hybrida collected for IAA analysis. b IAA concentrations and $\mathbf{c}$ IAA contents in leaves $(L)$ of different positions. d Relationship between leaf fresh mass and IAA concentration. $S A$ shoot apex including smallest enclosing leaves; $S M$ medium shoot position $(1.5-2.5 \mathrm{~cm}$ from the basal end); $S B$ stem base $(0-0.5 \mathrm{~cm})$. Mean and $S E$ from five individual cuttings, columns which do not share a common letter are significantly different $(P \leq 0.05$, Kruskal-Wallis test, $n=5)$. $\log$ $\log ^{-1}$ plot of IAA concentrations versus leaf mass of 20 individual leaves (L1-L4) from five individual cuttings

mounted on slides and stained for 2 min with $1 \%(\mathrm{w} / \mathrm{v})$ methylene blue and $1 \%(\mathrm{w} / \mathrm{v})$ Azur II in $1 \%(\mathrm{w} / \mathrm{v})$ aqueous borax at $60{ }^{\circ} \mathrm{C}$ before light microscopic examination, using a Zeiss Axiovert 135 (Jena, Germany) with an attached Zeiss Axiocam. After a rooting period of 14 days post excision, roots were counted, and then root length was determined as described in detail by Agulló-Antón et al. (2011). 
RNA isolation, northern blot analysis and Real-time PCR

Total RNA was extracted from $P$. hybrida cutting bases as described by Logemann et al. (1987). A Northern blot analysis was carried out as described by Ahkami et al. (2009). Four time points (0, 24, 72 and 144 hpe) were additionally analysed with Real-Time PCR. DNA was removed from RNA-extracts with RQ1 DNase (Promega, Madison, WI, USA), and first-strand cDNA was reverse transcribed using M-MLV RT RNase H reverse transcriptase (Promega) according to the manufacturer's protocol. The relative cDNA abundance was detected by the i-cycler iQ (Bio-Rad, Hercules, CA, USA) using iQ SYBR Green SuperMix (Bio-Rad). The mRNA levels were determined by relative quantification using petunia actin mRNA sequence as a reference related to the $0 \mathrm{~h}$ control. The Petunia GH3 gene (CV296522) was amplified from Petunia cDNA derived from the total RNA with the following specific primer pair (GH3 for: 5'-CACCGGCCCTTCA GTTCATC-3'; GH3 rev: 5'-CAGCAAGGCCACCAGGA GTC- $3^{\prime}$ ), resulting in a fragment of $507 \mathrm{bp}$.

Analysis of IAA, metabolites and enzyme activity

Extraction, clean-up and analysis of IAA were carried out according to a modified protocol as described by Müller et al. (2002). For extraction, $1 \mathrm{ml}$ methanol containing 10 pmol $\left({ }^{2} \mathrm{H}\right)_{2}$-IAA was added to a frozen sample together with five stainless steel balls (3 $\mathrm{mm}$ diameter) in a tube. The tube was immediately exposed to $60{ }^{\circ} \mathrm{C}$ for $20 \mathrm{~min}$ and the content subsequently disrupted for 20 min using a vibrating-ball micromill (Retsch MM301, Haan, Germany) at a vibration frequency of $30 \mathrm{~s}^{-1}$. After vortexing and incubation for $15 \mathrm{~min}$ at room temperature, the extract was centrifuged for $10 \mathrm{~min}$ at $14,000 \mathrm{~g}$, and the supernatant was collected. The residue was resuspended in $300 \mu \mathrm{l}$ methanol, incubated and then centrifuged as described above. Pooled supernatants were reduced to dryness in a vacuum centrifuge (Savant SPD 111 V, Fisher Scientific, Schwerte, Germany) at $40{ }^{\circ} \mathrm{C}$ for $30 \mathrm{~min}$ at $320 \mathrm{mbar}$ and thereafter at 200 mbar. The dried sample was dissolved in $50 \mu \mathrm{l}$ methanol by vortexing and subsequent ultrasonic treatment for $5 \mathrm{~min}$. After a short centrifugation, $200 \mu \mathrm{l}$ diethyl ether was added, and the closed tube was vortexed and then exposed to ultrasonic treatment, followed by centrifugation, as described above. An aminopropyl solid phase extraction column (Chromabond $\mathrm{NH}_{2}$ shorty $10 \mathrm{mg}$, Macherey-Nagel GmbH, Düren, Germany) was equilibrated with $200 \mu$ diethyl ether prior to application of the dissolved sample. The empty tube was flushed with $100 \mu \mathrm{l}$ diethyl ether, which was also applied on the column. The column was washed twice with $200 \mu$ diethyl ether, three times with $200 \mu \mathrm{l}$ of a mixture of chloroform/2-propanol $(2: 1, \mathrm{v} / \mathrm{v})$, three times with $200 \mu \mathrm{l}$ chloroform and finally with $100 \mu$ diethyl ether. The IAA fraction was eluted with three flushes of $200 \mu \mathrm{l}$ diethyl ether containing $4 \%$ acetic acid. Combined eluates were reduced to dryness in a stream of nitrogen at room temperature, redissolved in $20 \mu \mathrm{l}$ methanol, methylated with $200 \mu \mathrm{l}$ ethereal diazomethane, taken to dryness again and dissolved in $10 \mu \mathrm{l}$ ethyl acetate.

Separation and mass fragment analysis were conducted using a Varian Saturn 2200 ion-trap mass spectrometer connected to a CP-3800 gas chromatograph (Agilent, Santa Clara, CA, USA) fitted with a CombiPal autoinjector (CTC Analytics AG, Zwingen, Switzerland).

The GC settings were as follows: splitless injection $(1 \mu \mathrm{l})$ with 1-min pressure pulse at $24 \mathrm{psi}$; splitter opening 1:100 after $1 \mathrm{~min}$; columns: Phe-Sil retention gap $10 \mathrm{~m} \times 0.32 \mathrm{~mm}$ ID, ZB-50 $50 \%$ phenyl-50\% dimethylpolysiloxane $30 \mathrm{~m} \times 0.25 \mathrm{~mm}$ ID, $0.25 \mu \mathrm{m}$ film thickness, Phenomenex; carrier gas: He, $1 \mathrm{ml} \mathrm{min}^{-1}$, constant flow; temperature program: $1 \mathrm{~min}$ isothermally at $60{ }^{\circ} \mathrm{C}$, followed by a linear ramp at a rate of $40{ }^{\circ} \mathrm{C} \mathrm{min}-1$ to $150{ }^{\circ} \mathrm{C}$, isothermally for $6 \mathrm{~min}$ at $150{ }^{\circ} \mathrm{C}$, followed by a linear ramp of $20^{\circ} \mathrm{C} \mathrm{min}^{-1}$ to $250{ }^{\circ} \mathrm{C}$; transfer line temperature $230{ }^{\circ} \mathrm{C}$.

The MS settings were as follows: CI-MRM mode; positive ion detection; reactant gas methanol; temperatures of manifold and ion trap 60 and $200{ }^{\circ} \mathrm{C}$, respectively; axial modulation $4 \mathrm{~V}$; scan time $0.4 \mathrm{~s} \mathrm{scan}^{-1}$; multiplier offset $300 \mathrm{~V}$; emission current $50 \mu \mathrm{A}$; maximum ionization time $2 \mathrm{~ms}$; maximum reaction time $128 \mathrm{~ms}$; waveform: resonant. Settings for endogenous IAA were chosen as follows $(\mathrm{m} / \mathrm{z})$ : parent ion $=190(\mathrm{M}+\mathrm{H})^{+}$, diagnostic product ion $=130$, excitation amplitude $0.5 \mathrm{~V}$. A second channel analysing the isotopically labelled standard $\left({ }^{2} \mathrm{H}\right)_{2}$-IAA used the parent ion $(\mathrm{m} / \mathrm{z})=192(\mathrm{M}+\mathrm{H})^{+}$and the diagnostic daughter ion $(m / z)=132$. The amount of endogenous compound was calculated from the signal ratio of the unlabelled over the corresponding stable isotope-containing mass fragments. Recovery of the isotopically labelled standard was close to $50 \%$.

Carbohydrates were extracted in hot $80 \%$ aqueous ethanol and glucose, fructose, and sucrose were analysed via enzymatic assay in microplates according to Hajirezaei et al. (2000). Amino acids were analysed in the same extracts after derivatization with 6-aminoquinolyl- $N$-hydroxysuccinimidyl carbamate by ultra-high performance liquid chromatography using fluorescence detection (excitation at $300 \mathrm{~nm}$ and emission at $400 \mathrm{~nm}$ ) according to Zurbriggen et al. (2009). Extraction and determination of enzyme activities were conducted according to the method of Zrenner et al. (1995) with minor modifications, as described previously (Ahkami et al. 2009). 


\section{Statistics}

Because variances of data sets of IAA concentrations were not homogeneous among different groups according to the Hartley-Cochran-Bartlett test $(P \leq 0.05)$, differences between groups were tested using the Mann-Whitney $U$ test for comparisons between two groups, and using the Kruskal-Wallis test for comparisons between several groups $(P \leq 0.05)$. Measurements of metabolites and enzyme activities were compared using the $t$ test $(P \leq 0.05)$.

\section{Results}

Spatial distribution of IAA in $P$. hybrida cuttings

To elucidate the initial spatial distribution of IAA in the shoot tip cuttings and to assess the IAA pools possibly contributing to subsequent $\mathrm{AR}$ formation, first we analysed the IAA levels in different parts of cuttings at the time of excision from the donor plants. The different sections of an excised leafy petunia cutting are illustrated in Fig. 1a. Upon comparing leaves of different ages, IAA concentrations were highest in youngest leaves near the apex and decreased with lower position down to the fourth-eldest leaf (L4), the IAA level of which was similar to that of the lowest leaf (L6) close to the stem base (Fig. 1b). The L5 leaf was not analysed because its developmental stage was close to that of the L6 leaf. When focusing on the younger leaves, which showed the strongest variability in leaf size (L1-L4), we observed a strong inverse correlation between leaf weight and IAA levels. Thus, IAA concentrations followed a $\log \log ^{-1}$ plot versus leaf fresh mass, which explained $76 \%$ of the variation in IAA concentration (Fig. 1d). Inverse to the gradient in IAA concentration (Fig. 1b), and strongly determined by leaf weight, the absolute pool size (content) of IAA among leaves was, however, highest in the lowest leaf (Fig. 1c). Transversal sections of L6 revealed significantly higher IAA concentrations in the petiole than in the attached leaf base (Fig. 2a). Variation of IAA level within the leaf lamina was not significant; the tip showed higher mean levels, but there was strong variation among individual samples. Stem tissues revealed highest IAA concentrations; levels were even higher than those found in younger leaves (Fig. 2b). However, there was no gradient of IAA level between the three stem sections. Calculating the absolute size of IAA pools in the different parts of the cuttings revealed that at the time of excision, about $40 \%$ of IAA was located in the leaves, with $12 \%$ in the eldest leaf and approximately
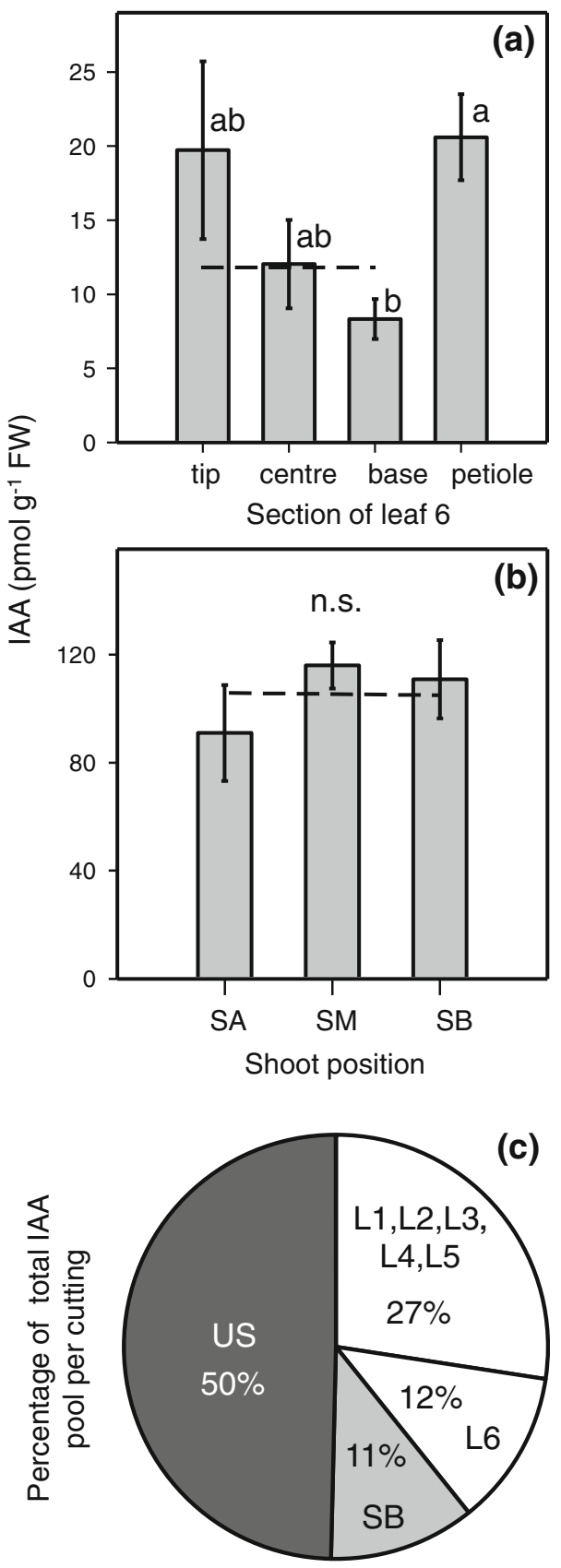

Fig. 2 a IAA concentrations in transversal sections of L6 leaf. b IAA concentrations in different stem positions. c Total IAA pool sizes in different cutting parts of $P$. hybrida. $L$ leaves of different positions, as shown in Fig. 1a. US complete upper stem above the stem base $(S B)$; tip, leaf section $0-1.5 \mathrm{~cm}$; centre, leaf section $>1.5 \mathrm{~cm}$ and $\leq 3 \mathrm{~cm}$; base, leaf section $>3 \mathrm{~cm}$. In $\mathbf{a}$ and $\mathbf{b}$, mean and $\mathrm{SE}$ from five individual cuttings. Columns which do not share a common letter are significantly different $(P \leq 0.05$, Kruskal-Wallis test, $n=5)$. Dithered lines indicate the mean IAA level in the complete lamina and shoot. IAA contents in $\mathbf{c}$ were calculated from IAA concentrations as illustrated in Fig. 1b and Fig. 2b (mean value of the three stem sections) and as estimated for $\mathrm{L} 5\left(14 \mathrm{pmol} \mathrm{g}^{-1} \mathrm{FW}\right.$ as mean value of L4 and L6) using the following fresh masses (mg): L1 (42), L2 (79), L3 (174), L4 (239), L5 (390), L6 (473), SB (65), US (290) 
Table 1 Influence of NPA treatment $(50 \mu \mathrm{M})$ on subsequent rooting of $P$. hybrida determined at day 14 post excision

\begin{tabular}{lllll}
\hline & Percentage of rooted cuttings $(\%)$ & No. of roots per rooted cutting & Length per root $(\mathrm{cm})$ & Total root length per planted cutting $(\mathrm{cm})$ \\
\hline Control & $95.8 \pm 4.2$ & $53.2 \pm 3.3$ & $1.4 \pm 0.06$ & $47.7 \pm 7.8$ \\
NPA & $20.8 \pm 4.2^{*}$ & $8.0 \pm 2.9^{*}$ & $0.6 \pm 0.04^{*}$ & $1.0 \pm 0.4^{*}$ \\
\hline
\end{tabular}

Mean values \pm SE of four replications (each consisting of six cuttings)

* Significant effect of NPA application ( $p \leq 0.05, t$ test or Mann-Whitney $U$ test in case of total root length)

$60 \%$ in the stem tissue, with $11 \%$ in the zone of subsequent root regeneration (Fig. 2c).

Influence of NPA on AR formation in P. hybrida cuttings

The auxin inhibitor NPA was employed to inhibit PAT and to evaluate the extent to which formation of ARs depends on basipetal transport from the upper shoot. Control cuttings showed intensive root formation. After 14 days, $96 \%$ of cuttings were rooted and showed $>50$ roots per cutting (Table 1). Spraying of cuttings with NPA severely inhibited AR formation (Fig. 3). Thus, only $21 \%$ of NPAtreated cuttings rooted until 14 days post excision, at very low intensity, as reflected by the low number of roots (Table 1). The overall rooting response as reflected by the total root length produced per planted cutting was reduced by the NPA treatment to $2 \%$ of the value of the controls.

The strong inhibition of AR formation in the cuttings in response to blocking of PAT was further highlighted by the anatomical studies. Control cuttings showed root meristemoids (new meristematic cells of the developing root meristems) at 72 hpe (Fig. 4e, f), globular root meristems at $144 \mathrm{hpe}(\mathrm{Fig} .4 \mathrm{i}, \mathrm{j}$ ) and dome-shaped root primordia at 192 hpe (Fig. 4m, n). In NPA-treated cuttings, formation of new meristematic cells was not observed until 72 hpe (Fig. 4g, h) and was only hardly detectable at 144 hpe (Fig. 4k, 1). In the same cuttings, few globular meristems appeared until 192 hpe when no dome-shaped primordia were observed (Fig. 4o, p).

Temporal course of IAA during AR formation in response to NPA treatment

We then investigated the response of the IAA level in the rooting zone to the excision of cuttings and its dependency on PAT. Cuttings were planted, and the temporal course of IAA levels in the stem base of a non-treated control and of NPA-treated cuttings was monitored. Considering that oldest leaves contain the highest initial amount of IAA among the leaves (Fig. 1c) and according to the previous studies identifying fully developed leaves of carnation shoot tip cuttings as an important IAA source for

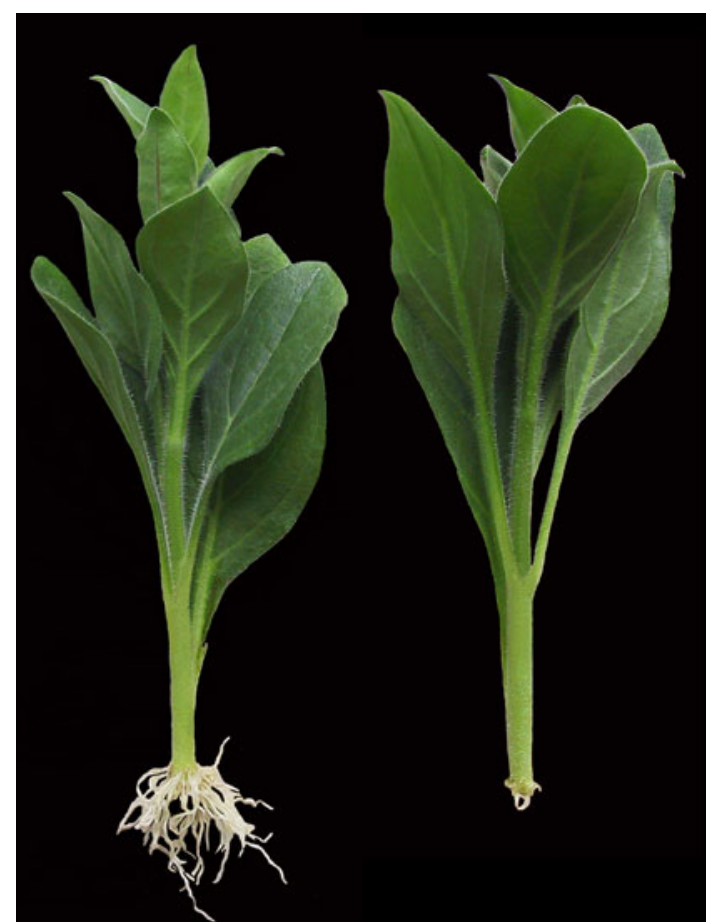

Fig. 3 Picture of overall rooting of representative control (left) and NPA-treated $(50 \mu \mathrm{M})$ cuttings of Petunia hybrida 'Mitchell' at 14 dpe. The background was digitally blackened

subsequent AR formation (Garrido et al. 2002), we also monitored the IAA levels in the L6 leaves. Because those showed some variation of IAA levels within transversal sections (Fig. 2a), leaf discs (7 mm diameter), equally distributed between the tip, middle and base position of the leaf lamina, were included in each sample.

IAA levels in L6 leaves during the course of AR formation are illustrated in Fig. 5a. Control cuttings maintained initial IAA concentrations until 48 hpe, followed by a continuous rise until the end of the experiment. As a result, IAA concentrations at 96 and 192 hpe were significantly higher by 88 and $208 \%$ compared with the initial level at the time of planting $(P \leq 0.05$, Mann-Whitney $U$ test, $n=5$ ). After spraying with NPA, IAA levels followed a trend similar to that observed for the control until 144 hpe but with some fluctuation (Fig. 5a). In contrast to the control, NPA-treated cuttings did not accumulate IAA in L6 leaves until the end of the experiment. 

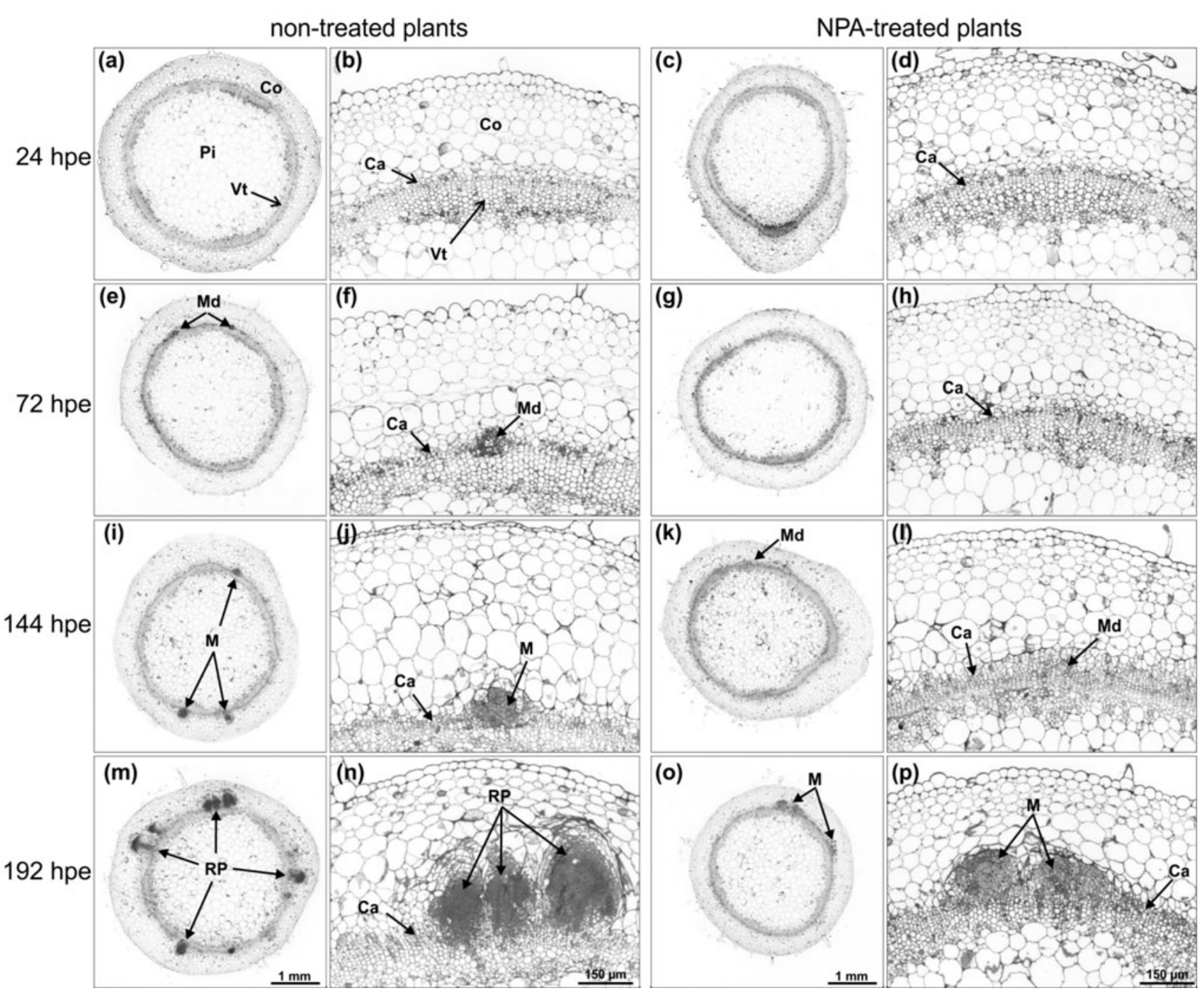

Fig. 4 Light microscopy of stem base of $P$. hybrida cuttings during rooting under non-treated and NPA-treated conditions. In all micrographs, semi-thin cross-sections from 1 to $4 \mathrm{~mm}$ above the excision site are shown. a, b 24 hpe control cuttings. c, d 24 hpe NPA-treated cuttings. e, f 72 hpe control cuttings. g, h 72 hpe NPA-treated

With regard to the stem base (Fig. 5b), IAA concentrations in control cuttings significantly increased during the first 2 hpe. This was followed by a transient decrease until $6 \mathrm{hpe}$ and a subsequent recovery to a maximum at 24 hpe. From 2 until 24 hpe, the stem base of control cuttings contained significantly higher IAA levels compared with those at the time of excision $(P \leq 0.05$, Mann-Whitney $U$ test, $n=5$ ); at 24 hpe the initial IAA level was exceeded by $+240 \mathrm{pmol} \mathrm{g}^{-1}$ fresh weight $(\mathrm{FW})$ $(+216 \%)$. IAA concentrations decreased thereafter (Fig. 5b), and from 96 hpe onwards remained below the initial level measured at the time of planting $(P \leq 0.05$, Mann-Whitney $U$ test, $n=5$ ). IAA in the stem base of cuttings. i, j 144 hpe control cuttings. k, I 144 hpe NPA-treated cuttings. m, n 192 hpe control cuttings. o, p 192 hpe NPA-treated cuttings. $C a$ cambium, $C o$ cortex, $M$ meristem of AR, $M d$ meristemoid of AR, $P i$ pith, $R P$ primordia of AR, $V t$ vascular tissue, hpe hours post excision

NPA-treated cuttings exhibited the same increase until 2 hpe, as was observed for the control (Fig. 5b), but thereafter showed a sharp decrease to initial levels. In response to the NPA treatment, the IAA peak that was observed in the control cuttings was completely suppressed from 4 until 24 hpe (IAA levels at 4, 6, 12, 24 hpe no different from IAA level at 0 hpe, $P \leq 0.05$, Mann-Whitney $U$ test, $n=5$ ). NPA-treated cuttings at 12 and 24 hpe showed significantly lower IAA levels in the stem base than in the control cuttings (Fig. 5b). After 72 hpe, NPA-treated cuttings showed the same low levels of IAA in the stem base as those observed for the control (Fig. 5b). 


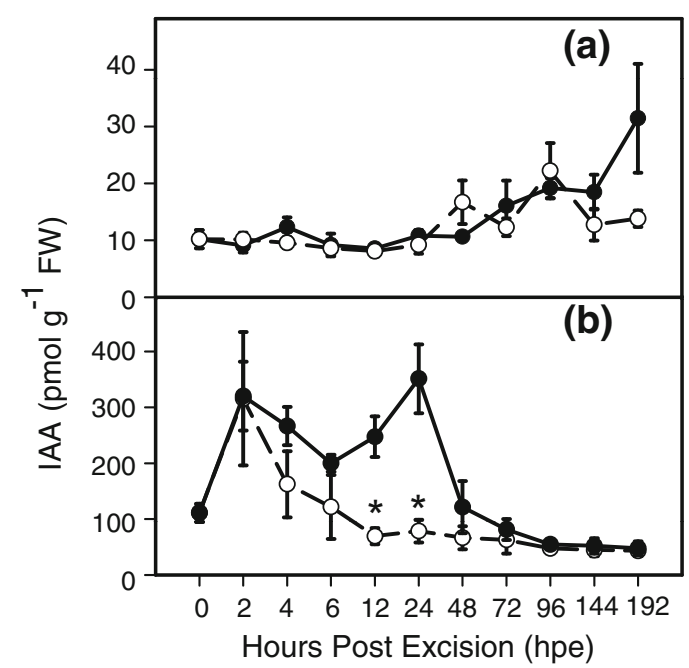

(c)

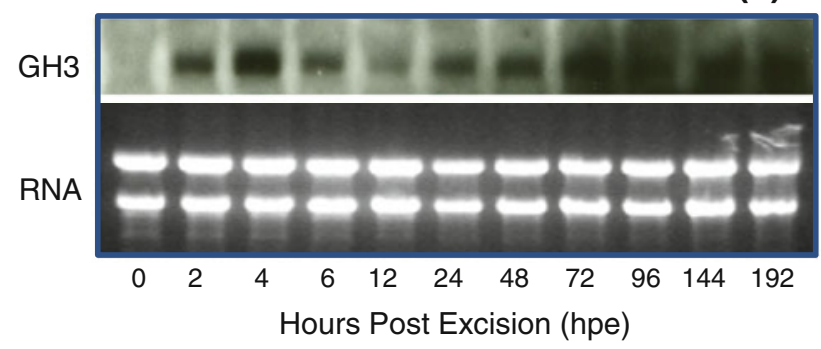

Fig. 5 Temporal course of IAA concentrations in the lowest leaf (L6, a) and the basal stem $(0.5 \mathrm{~cm}, \mathbf{b})$ of cuttings of $P$. hybrida during rooting under non-treated (solid line) and NPA-treated (dashed line) conditions ( $n=5$, each sample from two individual cuttings). Asterisks indicate a significant effect of the NPA treatment at the specified time after excision of cuttings (Mann-Whitney $U$ test, $P \leq 0.05$ ). c Transcript accumulation of auxin-responsive $G H 3$ gene in the basal stem of $P$. hybrida during rooting under standard (nontreated) conditions. Northern blot analysis was performed with $20 \mathrm{~g}$ RNA per sample, and separation on a $1.5 \%(\mathrm{w} / \mathrm{v})$ formaldehyde agarose gel. After transfer of RNA to a nitrocellulose membrane, it was hybridized to radioactively labelled cDNA fragments of the corresponding gene. The below picture shows the loading control of rRNA, the ratio of intensity of $28 \mathrm{~S}$ RNA to $18 \mathrm{~S}$ RNA (for total RNA) is $1: 1$

Transcript accumulation of auxin-responsive $G H 3$ gene during AR formation

To determine whether the time course of IAA in the stem base of control cuttings is reflected by the expression of an auxin-responsive gene, the transcript levels of the Petunia GH3 gene were monitored by Northern blot analysis. With a first increase to a maximum at $4 \mathrm{hpe}$, a decline thereafter, and a second increase beginning at 24 hpe (Fig. 5c), the GH3 expression showed a corresponding pattern to the IAA levels in the rooting zone (Fig. 5b). The induction of Petunia GH3 at 24 hpe and high expression at later stages (72 hpe, 144 hpe) were confirmed by quantitative RealTime PCR (Online Resource 1).

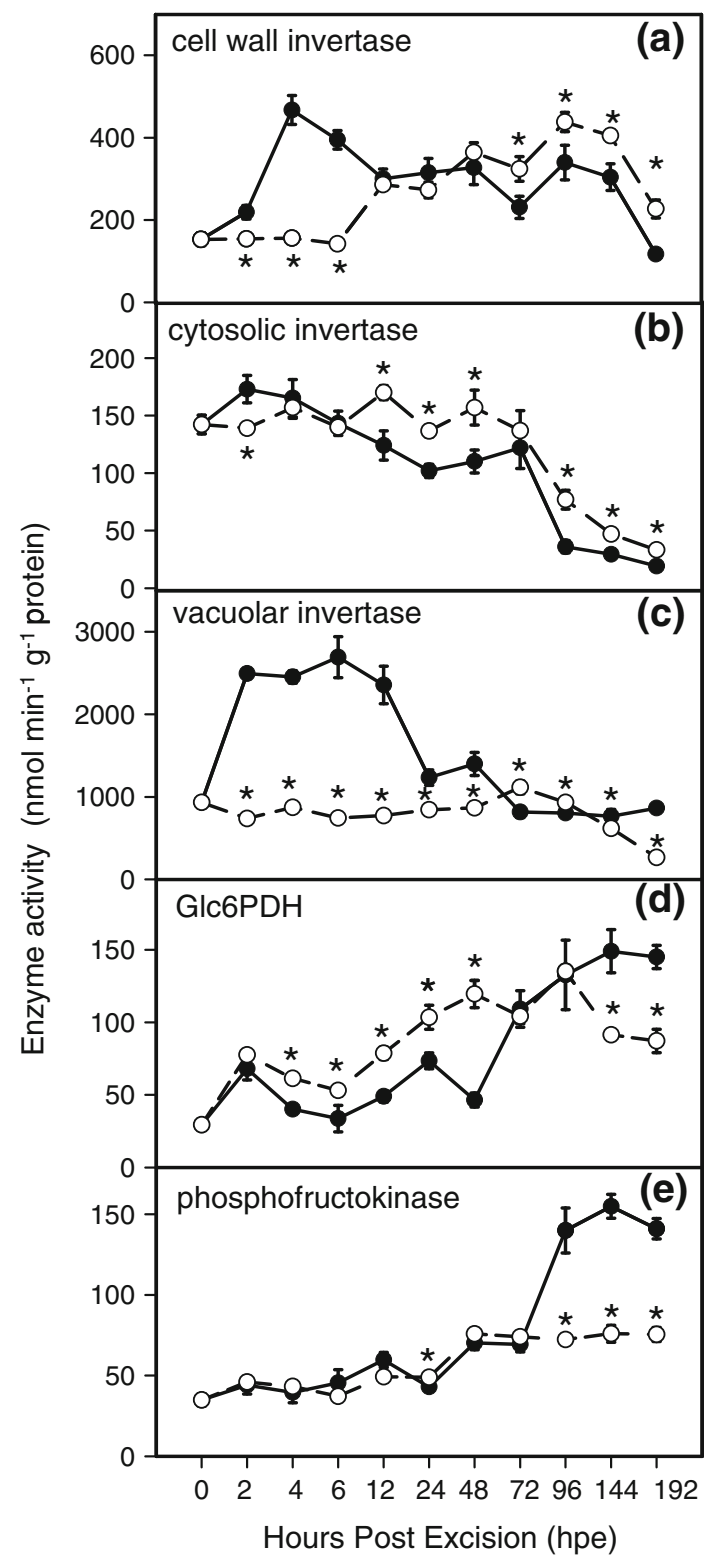

Fig. 6 Alterations in the enzyme activities involved in sucrose degradation, glycolysis and pentose phosphate pathways in the basal stem of $P$. hybrida during rooting under non-treated (solid line) and NPA-treated (dashed line) conditions. a Cell wall invertase, b cytosolic invertase, $\mathbf{c}$ vacuolar invertase, $\mathbf{d}$ glucose-6-phosphate dehydrogenase, e phosphofructokinase. Each value is represented by the mean of five independent replicates \pm SE. Asterisks indicate a significant effect of the NPA treatment at the specified time after excision of cuttings ( $t$ test, $P \leq 0.05$ )

\section{Influence of NPA on enzyme activities in the stem base}

To characterize further the effect of auxin transport on metabolic activity in primary metabolism during AR formation, the activities in the stem base of key enzymes involved in sucrose metabolism, the pentose phosphate pathway and glycolysis were analysed in response to NPA treatment. Results are illustrated in Fig. 6. In the 
non-treated cuttings, the activity of cell wall invertase increased soon after excision, peaking at $6 \mathrm{hpe}$, before decreasing to approximately its initial activity until 192 hpe. In contrast, cell wall invertase activity in NPAtreated cuttings remained at an initial low level until 6 hpe, and thereafter, increased up to twofold to levels similar to those of the control cuttings (Fig. 6a). The activity of cytosolic invertase showed a similar trend in both nontreated and NPA-treated cuttings, and decreased continuously during AR formation (Fig. 6b). The activity of vacuolar invertase increased up to two-and-half-fold in the stem base of non-treated cuttings and decreased until 192 hpe to reach approximately $30 \%$ of the initial value. However, activity of vacuolar invertase in the stem base of NPA-treated cuttings remained unchanged until 96 hpe and decreased thereafter (Fig. 6c). Furthermore, in the stem base of non-treated cuttings, the activity of glucose-6phosphate dehydrogenase (Glc6PDH) fluctuated in the first days of post excision and increased in the later course of AR formation (Fig. 6d). In NPA-treated cuttings, the activity of the same enzyme followed a similar trend; it was, however, less steep, with slightly higher activity than the control

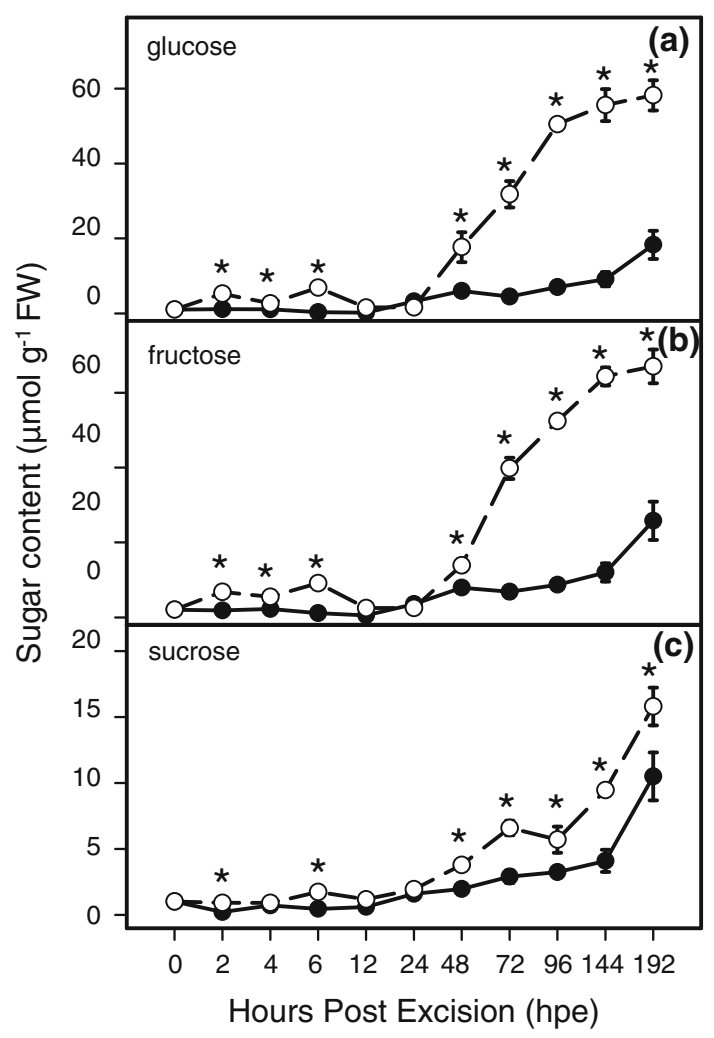

Fig. 7 Concentrations of soluble sugars in the basal stem of $P$. hybrida during rooting under non-treated (solid line) and NPA-treated (dashed line) conditions. a Glucose, $\mathbf{b}$ fructose, $\mathbf{c}$ sucrose. Each value is represented by the mean of five independent replicates $\pm \mathrm{SE}$. Asterisks indicate a significant effect of the NPA treatment at the specified time after excision of cuttings ( $t$ test, $P \leq 0.05$ ) cuttings until 48 hpe, and vice versa after 96 hpe. The activity of phosphofructokinase (PFK) was similar and did not change significantly in the stem base of both non-treated and NPA-treated cuttings up to $72 \mathrm{hpe}$. Thereafter, PFK activity increased significantly in the stem base of nontreated cuttings up to 192 hpe, while it remained unchanged in the stem base of NPA-treated cuttings (Fig. 6e).

Influence of NPA on sugar concentrations

in the stem base

The concentrations of soluble sugars were measured during rooting in the stem base of non-treated and NPA-treated cuttings to evaluate whether auxin transport changes the distribution of the sugars. In the stem base of non-treated cuttings, a continuous increase of glucose, fructose and sucrose was observed after 24 hpe, reaching 10-15-fold higher levels at 192 hpe relative to the initial values (Fig. 7a-c). In the stem base of NPA-treated cuttings, the increase in concentrations of soluble sugars was even more pronounced. At later time points, levels were three times higher for glucose and fructose, and 1.5-fold higher for sucrose compared with the levels measured in the stem base of non-treated cuttings (Fig. 7a-c).

Effect of NPA on soluble amino acids in the stem base

To determine whether auxin transport changes the composition of soluble amino acids, which are necessary for protein synthesis, during AR formation, the concentrations of total and individual amino acids were determined in the stem base of both non-treated and NPA-treated cuttings. The concentration of total amino acids showed a similar trend in both non-treated and NPA-treated cuttings, and increased continuously after 24 hpe. However, the levels reached at 144 and 192 hpe were about 30-40\% lower in the stem base of NPA-treated cuttings compared with the controls (Fig. 8a). The concentrations of the most abundant amino acids in the stem base, including glutamate, glutamine, aspartate, asparagine and proline, were compared. Glutamate concentrations showed a trend similar to the total amino acids; at 144 and $192 \mathrm{hpe}$, concentrations reached a twofold higher level in non-treated cuttings compared with NPA-treated cuttings (Fig. 8b). Similar but even more pronounced differences were found for glutamine concentrations at 144 and 192 hpe (Fig. 8c). Furthermore, a threefold increase of glutamine concentration until 2 hpe was observed only in non-treated cuttings; it was absent in NPA-treated cuttings (Fig. 8c). The concentrations of aspartate, even though on a lower level, followed a similar trend and showed the same response to NPA treatment as glutamate (Fig. 8d). In the stem base of non-treated cuttings, the concentration of asparagine 


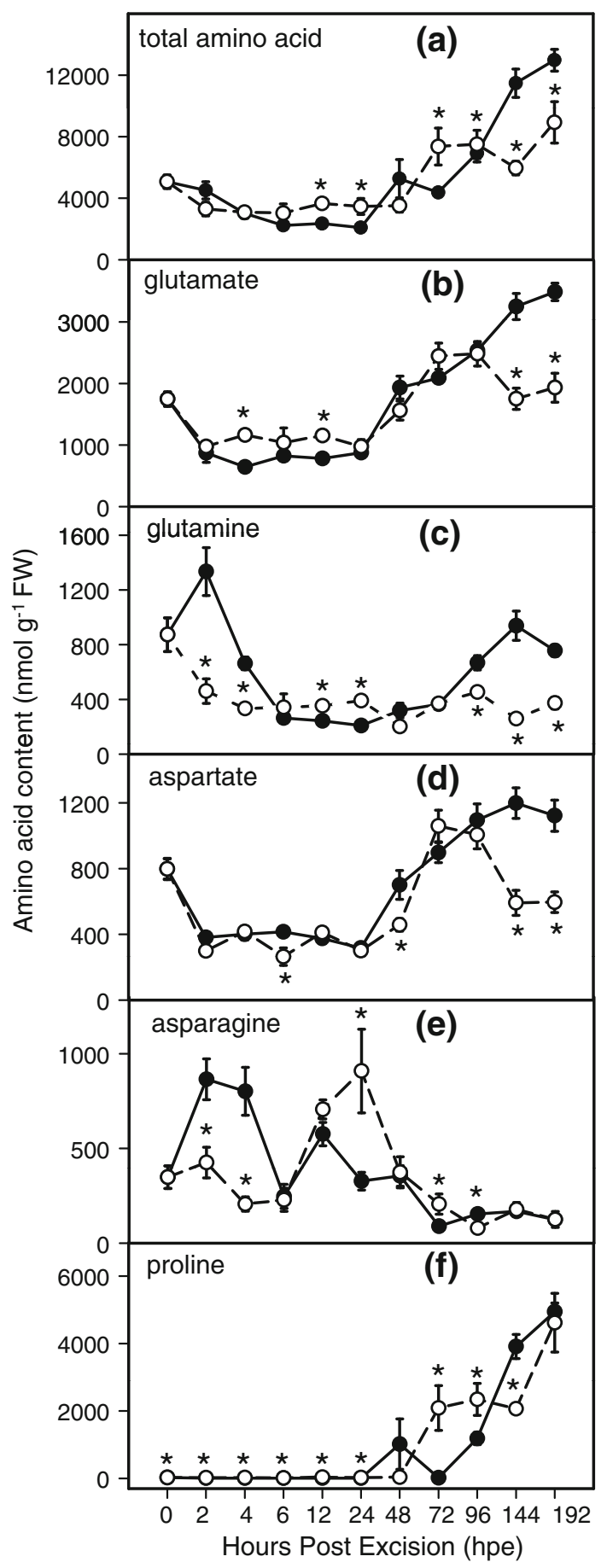

Fig. 8 Concentrations of amino acids in the basal stem of $P$. hybrida during rooting under non-treated (solid line) and NPA-treated (dashed line) conditions. a Total amino acids, b glutamate, c glutamine, $\mathbf{d}$ aspartate, $\mathbf{e}$ asparagine, $\mathbf{f}$ proline. Each value is represented by the mean of five independent replicates \pm SE. Asterisks indicate a significant effect of the NPA treatment at the specified time after excision of cuttings ( $t$ test, $P \leq 0.05$ )

increased until 2 hpe and fluctuated thereafter during AR formation to decrease to a lower level than the initial value at $192 \mathrm{hpe}$. In contrast, the asparagine concentration in the stem base of NPA-treated cuttings decreased continuously up to 6 hpe but thereafter showed a transient increase to levels that were higher than those measured in non-treated cuttings (Fig. 8e). The concentration of proline increased constantly after 48 hpe, up to 200 -fold at $192 \mathrm{hpe}$, compared with the initial values, in a similar manner for both non-treated and NPA-treated cuttings (Fig. 8f).

\section{Discussion}

In the present study, the initial spatial distribution of IAA in $P$. hybrida shoot tip cuttings at the time of excision and the relationship between subsequent homeostasis of IAA in the rooting zone, PAT and AR formation were investigated. In addition, the interrelations between auxin and metabolic response in the rooting zone were elucidated.

Spatial distribution of IAA in $P$. hybrida shoot tip cuttings before excision

We used GC-MS/MS to analyse the initial distribution of IAA in cuttings of $P$. hybrida at the time of excision. Concentrations found in the L3 leaves (Fig. 1b) and in the shoot apex (Fig. 2b) correspond to gas chromatographymass spectrometry data published for similar tissues of the same cultivar (Tobeňa-Santamaria et al. 2002). The strong negative relationship established for young Petunia leaves between leaf fresh mass and IAA concentration (Fig. 1d) is in accordance with corresponding relationships found for Arabidopsis, where IAA levels were high in those leaves that showed high rates of cell division but strongly decreased when leaf expansion was initiated (Ljung et al. 2001). Ljung et al. (2001) also reported that for young leaves of Nicotiana that were in transition from division to elongation growth, high IAA levels were restricted to the base and middle of the blade as zones of intense cell division. We did not observe such a gradient, and the IAA levels were generally low in the lamina of Petunia L6 leaves (Fig. 2a), which had about $50 \%$ of the maximum leaf length that we observed in old plants. This supports the assumption that cell division has almost completely ceased in L6 leaves. However, the higher IAA level in the petiole compared with the adjacent base (Fig. 2a) reflects the same accumulation pattern of IAA as observed in Arabidopsis and Nicotiana (Ljung et al. 2001; Müller et al. 2002), which indicates that active auxin transport occurred between the leaf and the stem of the Petunia cutting at the time of excision.

The similar IAA levels measured for the different stem positions of $P$. hybrida cuttings at the time of excision (Fig. 2b) are in accordance with data obtained for young shoots of other plant species (Nordström and Eliasson 
1991; Kojima et al. 2002; Jager et al. 2007). It has been shown that auxin can be produced in, and exported from, diverse parts of the young shoot such as the apex, young leaves, and developing and also expanding leaves (Ljung et al. 2001; Garrido et al. 2002; Woodward and Bartel 2005; Jager et al. 2007). Thus, the same IAA levels for the lower and upper shoot positions may indicate a current auxin influx not only from the apex but also from the lower leaves of Petunia cuttings.

The influence of PAT on auxin homeostasis and AR formation in P. hybrida

According to the current model, auxin travels through a combination of two processes: (1) rapid $\left(5-10 \mathrm{~cm} \mathrm{~h}^{-1}\right.$ ) non-directional transport that occurs in the vasculature and (2) slower PAT $\left(5-10 \mathrm{~mm} \mathrm{~h}^{-1}\right.$ ) (Friml and Palme 2002; Kerr and Bennett 2007). It has been further shown that conjunctions exist between these two routes. IAA from leaves can be loaded into the phloem, transported by this route (Morris and Kadir 1972; Borkovec et al. 1994) and then further transferred into the extravascular PAT pathway mainly at the shoot apex (Cambridge and Morris 1996). Specific influx [(auxin permease (AUX), like AUX (LAX)], specific efflux [pin-formed (PIN)], and multidrug resistance/P-glycoprotein [MDR/PGP] auxin carriers are involved, and their turnover, cycling and trafficking contribute to the asymmetric and dynamic nature of PAT (Morris et al. 2004; Kerr and Bennett 2007). The synthetic auxin transport inhibitor NPA is supposed to disrupt auxin efflux from the cell, even though the mode of action is still a matter of debate (Morris et al. 2004). It is thought that NPA acts via binding to a putative NPA-binding receptor protein, which is assumed to be located on the cytoplasmic face of the plasma membrane. It has been reported that inhibitors of PAT prevent the traffic of PIN1 and other rapidly cycled proteins to and from the plasma membrane in Arabidopsis root cells (Geldner et al. 2001). NPA has also been shown to interact with members of the MDR/ PGB family in Arabidopsis.

The role of PAT in AR formation of cuttings has been studied intensively in carnations. Guerrero et al. (1999) measured the transport of labelled IAA through $1-\mathrm{cm}$ long stem sections of freshly excised carnation cuttings. First and most of the labelled IAA passed the $1-\mathrm{cm}$ section after a transport period of $1-2 \mathrm{~h}$ and $8 \mathrm{~h}$, respectively, while application of NPA to the stem sections inhibited basipetal transport by $62-91 \%$, depending on the particular test conditions. Garrido et al. (2002) showed also that labelled IAA applied to mature leaves of cuttings was transported to the stem base and that excision of complete leaves, but not of the apex and of youngest leaves, inhibited rooting, while detached leaves could be partially substituted by auxin application to the stem. Application of NPA to the cuttings also resulted in inhibition of rooting in other plant species (Nordström and Eliasson 1991; Liu and Reid 1992; Koukourikou-Petridou and Bangerth 1997). In accordance to these studies, NPA severely inhibited and delayed the development of root primordia in P. hybrida (Figs. 3, 4) and decreased the overall intensity of rooting determined at 14 days post excision by $98 \%$ (Table 1 ). A parallel analysis of IAA level highlighted the relationships between PAT, auxin accumulation in the rooting zone and different developmental phases in Petunia cuttings. The significant increase of IAA in the stem base of control cuttings between 2 and 24 hpe (Fig. 5b), which was followed by the formation of first meristematic cells at 72 hpe (Fig. 4e, f), contrasted with the elimination of the 24-h peak of IAA (Fig. 5b) and subsequent severe inhibition of adventitious rooting in NPAtreated cuttings (Figs. 3, 4; Table 1). This provides evidence for the essential contribution of PAT and the early accumulation of IAA in the rooting zone to spontaneous AR formation in Petunia cuttings in response to excision.

The kinetic of IAA levels in the rooting zone of control cuttings indicates two overlapping peaks, with maxima at 2 and 24 hpe, reflecting a strong regulation of auxin homeostasis soon after excision of Petunia. Similar fast changes of IAA levels have also been detected in the rooting zone of some other plant species (Blakesley et al. 1991). The observation that the 24-h peak of IAA was completely prevented by application of NPA provides evidence that this peak was the outcome of PAT. However, the first IAA maximum at 2 hpe was not prevented by NPA. We applied the NPA immediately after, but not before, excision of cuttings because we did not want to manipulate the initial auxin homeostasis in the cuttings before severance. Considering also the initial distribution of IAA pools within the cutting (Fig. 2c) and the speed of PAT, as discussed above, the missing effect of NPA until 2 hpe may reflect a lag phase between NPA application and its action on the cutting. NPA action may also have been underestimated by the IAA analyses of the complete stem (further discussed below). Nevertheless, the first IAA peak may also reflect transport in the phloem, local synthesis or mobilization from conjugates.

Wounding is an intrinsic process when cuttings are excised from donor plants, and we have already detected a strong increase of the wound-responsive hormone jasmonic acid in the stem base of Petunia cuttings during the first 30 min after excision (Ahkami et al. 2009). There are indications in the literature that wounding of plant tissues (Sztein et al. 2002) and jasmonates (Grsic et al. 1999; Sun et al. 2009) can stimulate IAA biosynthesis in plant tissues.

According to the inhibition of auxin efflux, it has been observed that auxins accumulate in cells treated with blockers and that application of NPA to stems stimulates 
auxin accumulation in the tissues above the NPA-treated region (Morris et al. 2004). Regarding the initial size of the IAA pool and the particular accumulation of IAA in the petiole of L6 leaves (Figs. 1c, 2a), we monitored the IAA level in L6 leaves as potential source organs for auxin export. As illustrated in Fig. 5a, IAA did not accumulate significantly in L6 leaves of NPA-treated cuttings compared with the non-treated ones. This provides no supportive indication of a predominant role of the L6 leaf as source organ for providing the auxin accumulation in the rooting zone. However, the observed oscillation of IAA levels in the NPA-treated cuttings may reflect a feedback inhibition of IAA biosynthesis in response to trapping of IAA, which has been found in expanding leaves of Arabidopsis (Ljung et al. 2001). Distinct blocking of auxin transport in separate parts of Petunia cuttings should be done in future studies, to elucidate these relationships. Interestingly, the IAA level showed a continuous increase after 72 hpe only in L6 leaves of non-treated cuttings; at 192 hpe, it reached a level significantly higher than the initial level (Fig. 5a). Considering that roots were formed in the non-treated cuttings during this period and regarding the possibility of de novo IAA biosynthesis in roots, which has been shown for Arabidopsis (Ljung et al. 2001), rootsourced auxin may have contributed to this increase.

\section{Auxin action and AR formation}

We analysed the Petunia GH3 gene expression in the stem base of non-treated control cuttings as an early marker of auxin activity (Hagen and Guilfoyle 1985) to obtain information on the involvement of auxin action at certain developmental stages of AR formation. The time course of GH3 gene expression (Fig. 5c) followed the trend of the IAA level (Fig. 5b), while the strong increase of transcript level at 4 hpe indicated a lag phase of ca. $2 \mathrm{~h}$ behind the peaking of IAA. Considering the dose-dependent induction of the GH3 promoter by active auxin, as shown in transgenic tobacco (Hagen et al. 1991; Li et al. 1999), these observations support the view that early auxin activity is causally involved in initiating the primary events of ARF in Petunia. Regarding also the fact that several GH3 genes in Arabidopsis encode IAA-amido synthetases, which are important for maintaining auxin homeostasis by conjugating excess IAA to amino acids (Staswick et al. 2005; Wang et al. 2007), GH3 expression may also contribute to auxin conjugation in Petunia cuttings to reduce the level of active auxin and thus to avoid inhibitory influences during later processes of AR formation (De Klerk et al. 1999). However, elucidation of these processes was not in the focus of the present study and requires further investigations involving quantification of IAA conjugates and $G H 3$ monitoring in response to NPA treatment.
Despite their broad use, the physiological mechanisms underlying the AR-induction by auxins are still far from being understood (Ludwig-Müller 2009). According to a recent model, plant phospholipase 2 is involved in auxin signal transduction during AR formation, and a large family of auxin-induced gene products (so-called 'Aux/ IAA' proteins), auxin-responsive transcription factors (auxin response factors) and ARGONAUTE1 are involved in auxin-induced gene expression controlling the cellular events such as changes in cell cycle and cytoskeleton, tissue reorganization and cell wall modification (LudwigMüller 2009). Specific GH3 genes may have particular functions in AR formation, which go beyond their role in auxin homeostasis, as supported by studies with Arabidopsis seedlings (Sorin et al. 2005). Recently, Gutierrez et al. (2012) showed that three auxin-inducible GH3 genes are required for positive regulation of light-induced AR formation in Arabidopsis. They act by mediating the upstream interaction of three auxin response factors and downstream modulation of jasmonic acid homeostasis (Gutierrez et al. 2012).

Auxin might affect the root formation by acting directly in the cambium cells that initiate root primordia or indirectly through its engagement in the overall metabolism (Altman and Wareing 1975). Regarding the role of auxin in cell division and elongation, a complex interaction between auxin, cytokinin, cyclins and cyclin-dependent kinases (CDKs) governs the plant cell cycle (Hartig and Beck 2006; Komaki and Sugimoto 2012) Auxin treatment stimulated expression of cyclins including mitotic B1 cyclins in Arabidopsis (Ferreira et al. 1994; Richard et al. 2002), and expression of cyclin genes and of CDKs has already been related to auxin-induced AR formation (Lindroth et al. 2001; Neves et al. 2006). When Petunia cuttings experienced the same rooting conditions as applied to the controls in the present study, the transcript of a Petunia $C y c B 1$ encoding a mitotic B1 cyclin accumulated in the stem base at 48 hpe (Ahkami et al. 2009). Based on the observation of IAA accumulation until 24 hpe (Fig. 5b), this may have contributed to the induction of Petunia $C y c B 1$ and thereby stimulated the initiation of cell division. Furthermore, other genes such as SCARECROWlike genes may be involved; expression has already been shown to be stimulated in rooting-competent cuttings of Pinus radiata and Castanea sativa by auxin treatment before activation of cell division (Sánchez et al. 2007).

Involvement of PAT and auxin homeostasis in the response of primary metabolism during AR formation

Plant meristems are utilization sinks, in which cell division activity governs sink strength (Hartig and Beck 2006). 
Monitoring of enzyme activities in the stem base of $P$. hybrida cuttings during AR formation revealed that some enzymes, such as cell wall and vacuolar invertases, as well as PFK, were modulated at specific root developmental stages and that these modulations were subjected to NPA treatment (Fig. 6). While the activity of invertases showed a maximum during the first hours of post excision in nontreated cuttings, the early increases of cell wall invertase (Fig. 6a) and of vacuolar invertase (Fig. 6c) were prevented by NPA application, indicating that PAT contributed to the increase in activities of these sucrose degrading enzymes. These results reflect a specific relationship between basipetal auxin transport and extracellular and vacuolar invertases, and suggest that auxin may regulate the activity of enzymes in the sink establishment phase of AR formation in Petunia cuttings. Importantly, one of the proposed functions of cell wall invertase is to act as a linker between hormonal responses and primary metabolism (Roitsch and Gonzalez 2004). Even though there is indication in literature that vacuolar and cell wall invertases can be stimulated by auxin (Morris and Arthur 1984, Lee et al. 1997), the underlying mechanisms are far from being understood. The dominant mechanism that determines steady-state level of invertases is a highly responsive transcriptional regulation; however, invertases are further controlled at post-translational level and via protein trafficking and transcript turnover (Roitsch and Gonzalez 2004; Albacate et al. 2011). Yun et al. (2002) could counteract a rapid repression of vacuolar invertase in excised etiolated hypocotyl segments of mung bean by incubation with IAA, while the auxin treatment increased enzyme activity and the level and half-life of transcripts of the vacuolar invertase gene $V R-A I l$. Responses to inhibitors of polymerase II and of protein biosynthesis further supported the view that IAA enhanced transcript stability. Proels et al. (2003), who described the full genomic sequence and expression pattern of the LIN5 gene coding for an extracellular invertase in tomato, provided evidence that auxin stimulated expression of this gene while auxin responsiveness was mediated via a $1.6-\mathrm{kb} \operatorname{Lin} 5$ promoter fragment.

The temporal courses of IAA and invertase activities in the stem base reveal that NPA treatment-reduced activities of cell wall (4 hpe, Fig. 6a) and of vacuolar invertases ( 2 hpe, Fig. 6c) before a significant reduction in IAA level were detected (12 hpe, Fig. 5b). PAT in stems occurs in the xylem parenchyma cells, the vascular cambium and its partially differentiated derivative (Gälweiler et al. 1998; Morris et al. 2004). Thus, IAA might have responded earlier to the NPA treatment in particular tissues and cell compartments, and thereby influenced invertase activity before a significant change of IAA level was detected in the complete stem base. Future studies of spatial and cellular distribution of auxin activity by use of auxin-responsive promoters in response to NPA treatment may elucidate these relationships.

Comparing enzyme activities with measured sugar levels, it has to be considered that activities of invertases were determined for certain cell compartments (apoplast, cytosol, vacuole), whereas sugar levels reflect the mean situation of the whole stem base of the cuttings. Furthermore, sugar levels may be additionally influenced by fluxes or metabolic events which are not limited by those enzymes analysed in this study. Considering the period between 4 and 12 hpe, NPA treatment decreased the activities of cell wall and vacuolar invertases but slightly enhanced the levels of glucose and fructose. Apart from the influence of cell compartments, this may indicate that NPA also inhibited utilisation of hexoses. As already discussed above, the expression of mitotic cyclin genes is typical for cells shortly before they divide (Ferreira et al. 1994), and an enhanced expression of a Petunia $C y c B 1$ gene was detected in $P$. hybrida at 48 hpe when rooting conditions were the same as applied to the control cuttings in the present study (Ahkami et al. 2009). Considering, that replication of DNA, RNA and protein synthesis occurs before the mitosis phase of the cell cycle (Hartig and Beck 2006), there is a need of carbon skeletons before cell division starts. In conclusion, the slightly higher sugar levels in NPA-treated cuttings compared to the controls between 4 and 12 hpe may reflect a higher ratio between hexose consumption due to auxin-stimulated cell division on the one side and sucrose delivery and hexose release on the other side. However, the data of Glc6PDH and of PFK do not provide indication that these enzymes were primarily bottlenecks of glucose utilization during this early phase. Although subsequent root formation was delayed using the blocker of PAT (Fig. 4), soluble sugars, particularly, hexoses accumulated more strongly in the stem base of NPAtreated cuttings beginning $48 \mathrm{~h}$ after excision compared with the controls (Fig. 7). From a first point of view, these results seem to contradict findings that auxin application to the stem base of cuttings of other plant species enhances the sugar level in the rooting zone (Altman and Wareing 1975; Husen and Pal 2007; Agulló-Antón et al. 2011). However, it has to be taken into account that in the present study, the role of "natural auxin level" in response to excision of cuttings was investigated. In the studies mentioned above, applied auxin probably enhanced auxin concentration in the rooting zone to much higher levels so that the balance between the responses at sink establishment level (modifying carbohydrate influx) versus root development level (modifying carbohydrate utilization) might have been different in our study. Based on our observations, we conclude that the elevated sugar accumulation in NPA-treated Petunia cuttings during the later 
Fig. 9 A postulated model of relationship between PAT, auxin accumulation, primary metabolism and AR formation in Petunia cuttings in response to excision from the donor plant. Red solid arrows indicate processes that are dependent on PAT and are correlated with the resulting auxin peak at 24 hpe in the rooting zone. Red dashed arrows indicate additional processes which are hypothetically depending on PAT as supported by data of the present study and of Ahkami et al. (2009). Thin black arrows with question mark show possible interrelations between GH3 induction, auxin metabolism and cellular events of AR formation. Further details regarding different stages and phases of AR formation in petunia cuttings are described in Ahkami et al. (2009). PAT polar auxin transport, $C W$ invertase cell wall invertase, $P F K$ phosphofructokinase, Glc6PDH glucose-6-phosphate dehydrogenase, hpe hours post excision

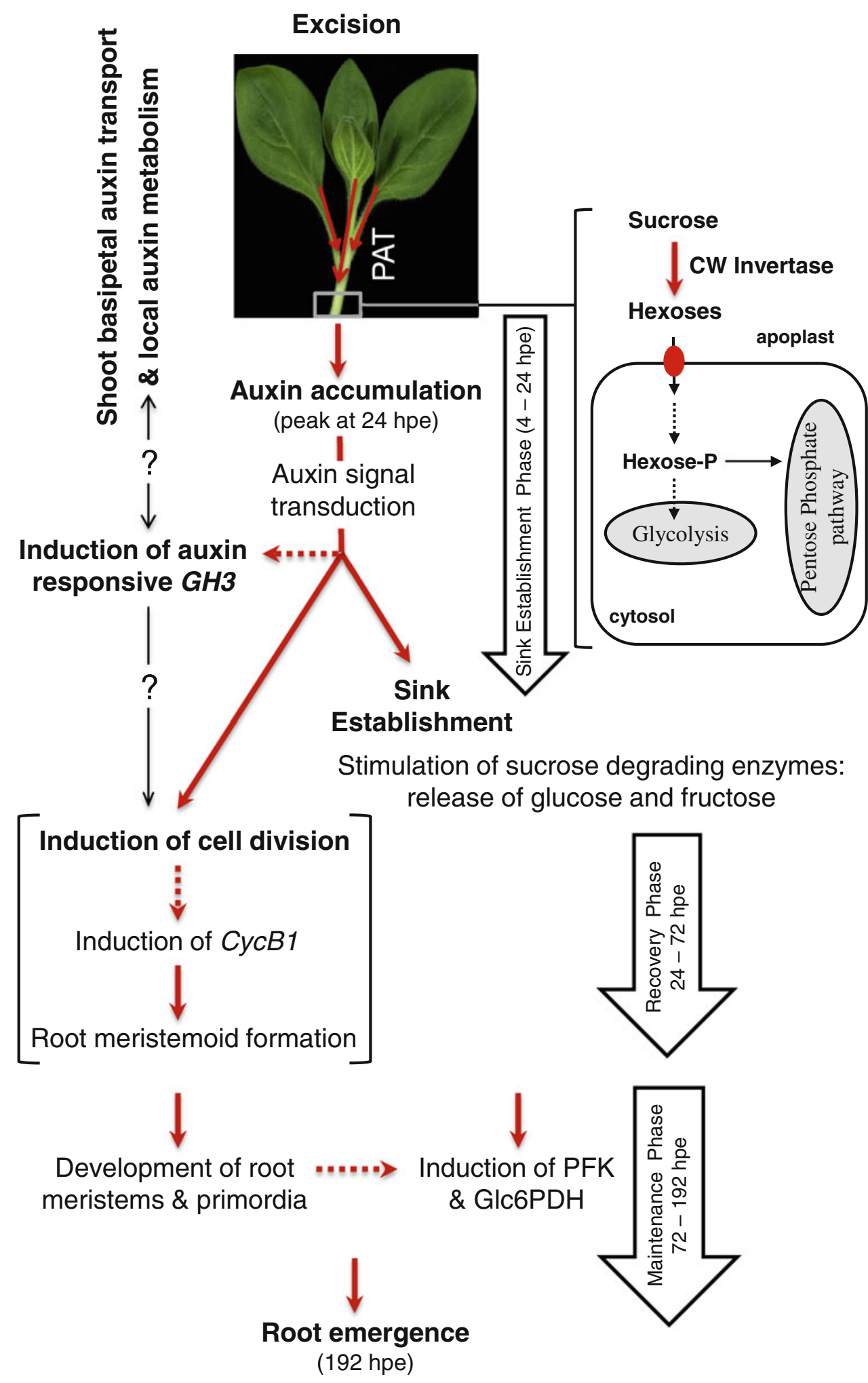

stages of AR formation is not directly affected by the lower auxin level until 24 hpe. This phenomenon is rather the outcome of the lower utilization of carbohydrates due to the strongly inhibited root formation. This conclusion is strongly supported by our finding that during the period after 96 hpe, the NPA-treated cuttings demonstrated significantly lower activities of PFK and of Glc6PDH than the control cuttings.

Amino acids are needed during AR formation because they provide essential components for protein synthesis 
required for cell division, elongation and function. In accordance with findings of earlier studies (Ahkami et al. 2009), total amino acids, glutamate, glutamine and aspartate accumulated in the rooting zone of control cuttings in this study as well. The highest levels were observed during the period following 96 hpe (Fig. 8), when root meristems and primordia were formed (Fig. 3). Accumulation of those amino acids was significantly lower in NPA-treated cuttings (Fig. 8b-d). Interestingly, inhibition of AR formation was associated with increased sugar levels but with decreased amino acid levels, even though both can be considered as important resources for root development (Haissig 1986). This discrepancy suggests that the intensity of influx and biosynthesis of amino acids in the rooting zone is directly related to differentiation and growth of ARs (Fig. 3), whereas the sugar level in the rooting zone, which is also highly dependent on the strength of the carbon source in the cutting (Rapaka et al. 2005), reflects the balance between influx and utilization of carbon. In this context, Petunia cuttings reveal high carbon assimilation, comparable to that of intact donor plants even at irradiance lower than that used in the present study (Klopotek et al. 2012).

Interestingly, NPA treatment led to inhibition of the early increase of glutamine and asparagine in the rooting zone in the sink establishment phase (Fig. 8c, e). These two compounds belong to the group of amino acids transported in the phloem (Urquhart and Joy 1982; Lohaus and Moellers 2000), and asparagine is suggested to be the main nitrogen transport compound in the initiating roots of cuttings (Suzuki and Kohno 1983). Considering on the one hand, the possible roles of PAT and early auxin accumulation (Fig. 4b) in driving sucrose utilization via stimulation of cell wall and vacuolar invertase (Fig. 6a, c), and on the other hand the mechanism of co-transport of sucrose and amino acids in the phloem (Lalonde et al. 2004), the lower levels of both amino acids in the stem base of NPAtreated cuttings may be the result of decreased apoplastic unloading of sucrose.

A strong accumulation of proline was found at later stages of AR formation, while similar levels were monitored in both non-treated and NPA-treated cuttings (Fig. 8f). These results do not support a role of PAT or of auxin homeostasis in proline accumulation during AR formation in Petunia cuttings. This is in contrast with the observations that auxin application increased the levels of proline in mung bean hypocotyls (Kuraishi et al. 1967) and transcripts of proline-rich proteins (PRPs) involved in lateral root formation in Arabidopsis and carrot (Ebener et al. 1993; Neuteboom et al. 1999; Bernhardt and Tierney 2000). However, it has been suggested that auxin acts as a regulator of PRP genes in a particular time- and concentration-dependent manner (Thomas et al. 2003).

\section{Conclusive model}

Overall, our study clearly shows that spontaneous AR formation in leafy stem cuttings of $P$. hybrida is dependent on PAT and on resulting auxin homeostasis in the rooting zone. A respective model of the relationship between PAT, auxin, primary metabolism and AR formation is postulated and illustrated in Fig. 9. After excision of cuttings, PAT enables the accumulation of free auxin in the rooting zone, where it (1) contributes to the establishment of the new sink via stimulation of cell wall and vacuolar invertases and (2) induces the first cell divisions of the new root meristems. After PAT-dependent induction of root meristems and sink establishment, the decrease of auxin levels allows for subsequent root development, which in turn stimulates the entry of glucose into glycolysis and the pentose phosphate pathway as reflected by the NPAinhibited activation of PFK and G6PDH. Stimulated glycolysis and pentose pathway generate the energy and carbon skeletons to be used for synthesis of amino acids, proteins and nucleic acids. The present data further support the assumption that accumulation of free auxin contributes to induction of GH3 gene while previous results (Ahkami et al. 2009) suggest involvement of Petunia $C y c B 1$ gene in induction of cell division. GH3 may stimulate auxin conjugation thereby reducing the level of active auxin after 24 hpe and may be further involved in initiation of cellular events. Activity of sucrose degrading enzymes provides the hexoses needed for supply of energy and of carbon to cell proliferation, differentiation and growth. Considering the effects of sugars, particularly of hexoses on gene expression (Rolland et al. 2006), released hexoses may be further involved in the control of cell cycle (Hartig and Beck 2006) and modification of auxin homeostasis (Sairanen et al. 2012) and signal transduction (Mishra et al. 2009), while the steady-state levels of individual sugars reflect the balance between the influx and degradation of sucrose and the utilization of hexoses via glycolysis and pentose phosphate pathway.

Acknowledgments We thank Sabine Czekalla, IGZ, for her skilful technical assistance. We thank Klaus Fricke, IGZ, for his great job in establishing the GC-MS/MS analysis and Petra Düchting, Ruhr University Bochum, Germany for her support. This work was funded by the Pakt für Forschung und Innovation of the Leibniz-Gemeinschaft, Germany, and supported by the states of Saxony-Anhalt and Brandenburg, the Free State of Thuringia and the Federal Republic of Germany. 
Open Access This article is distributed under the terms of the Creative Commons Attribution License which permits any use, distribution, and reproduction in any medium, provided the original author(s) and the source are credited.

\section{References}

Agulló-Antón MA, Sánchez-Bravo J, Acosta M, Druege U (2011) Auxins or sugars: what makes the difference in the adventitious rooting of stored carnation cuttings? J Plant Growth Regul 30:100-113

Ahkami AH, Lischewski S, Haensch KT, Porfirova S, Hofmann J, Rolletschek H, Melzer M, Franken P, Hause B, Druege U, Hajirezaei MR (2009) Molecular physiology of adventitious root formation in Petunia hybrida cuttings: involvement of wound response and primary metabolism. New Phytol 181:613-625

Albacate A, Grosskinsky DK, Roitsch TH (2011) Trick and treat: a review on the function and regulation of plant invertases in the abiotic stress response. Phyton 50:181-204

Altman A, Wareing PF (1975) Effect of IAA on sugar accumulation and basipetal transport of C14-labeled assimilates in relation to root formation in Phaseolus vulgaris cuttings. Physiol Plant 33:32-38

Baadsmand S, Andersen AS (1984) Transport and accumulation of indole-3-acetic acid in pea cuttings under two levels of irradiance. Physiol Plant 61:107-113

Bernhardt C, Tierney ML (2000) Expression of AtPRP3, a prolinerich structural cell wall protein from Arabidopsis, is regulated by cell-type-specific developmental pathways involved in root hair formation. Plant Physiol 122:705-714

Blakesley D (1994) Auxin metabolism and adventitious root initiation. In: Davis TD, Haissig BE (eds) Biology of adventitious root formation. Plenum Press, New York, pp 143-153

Blakesley D, Weston GD, Hall JF (1991) The role of endogenous auxin in root initiation. Part I: evidence from studies on auxin application and analysis of endogenous levels. Plant Growth Regul 10:341-353

Blažková A, Sotta B, Tranvan H, Maldiney R, Bonnet M, Einhorn J, Kerhoas L, Miginiac E (1997) Auxin metabolism and rooting in young and mature clones of Sequoia sempervirens. Physiol Plant 99:73-80

Borkovec V, Didehvar F, Baker DA (1994) The biosynthesis and translocation of C14 IAA in Ricinus communis. Plant Growth Regul 15:137-141

Cambridge AP, Morris DA (1996) Transfer of exogenous auxin from the phloem to the polar auxin transport pathway in pea (Pisum sativum L.). Planta 199:583-588

De Klerk GJ, van der Krieken W, de Jong J (1999) Review the formation of adventitious roots: new concepts, new possibilities. In Vitro Cell Develop Biol Plant 35:189-199

Druege U (2009) Involvement of carbohydrates in survival and adventitious root formation of cuttings within the scope of global horticulture. In: Niemi K, Scagel C (eds) Adventitious root formation of forest trees and horticultural plants-from genes to applications. Research Signpost, Kerala, pp 187-208

Ebener W, Fowler TJ, Suzuki H, Shaver J, Tierney ML (1993) Expression of Dcprp1 is linked to carrot storage root-formation and is induced by wounding and auxin treatment. Plant Physiol 101:259-265

Ferreira PC, Hemerly AS, Engler JD, van Montagu M, Engler G, Inze D (1994) Developmental expression of the Arabidopsis cyclin gene cyclAt. Plant Cell 6:1763-1774
Friml J, Palme K (2002) Polar auxin transport—old questions and new concepts? Plant Mol Biol 49:273-284

Gälweiler L, Guan C, Müller A, Wisman E, Mendgen K, Yephremov A, Palme K (1998) Regulation of polar auxin transport by AtPIN1 in Arabidopsis vascular tissue. Science 282:2226-2230

Garcia Gomez ML, Sanchez Romero C, Barcelo Munoz A, Heredia A, Pliego Alfaro F (1994) Levels of endogenous indole-3-acetic acid and indole-3-acetyl-aspartic acid during adventitious rooting in avocado microcuttings. J Exp Bot 45:865-870

Garrido G, Guerrero JR, Cano EA, Acosta M, Sanchez-Bravo J (2002) Origin and basipetal transport of the IAA responsible for rooting of carnation cuttings. Physiol Plant 114:303-312

Geldner N, Friml J, Stierhof YD, Jurgens G, Palme K (2001) Auxin transport inhibitors block PIN1 cycling and vesicle trafficking. Nature 413:425-428

Grsic S, Kirchheim B, Pieper K, Fritsch M, Hilgenberg W, LudwigMüller J (1999) Induction of auxin biosynthetic enzymes by jasmonic acid and in clubroot diseased Chinese cabbage plants. Physiol Plant 105:521-531

Guerrero JR, Garrido G, Acosta M, Sanchez-Bravo J (1999) Influence of 2,3,5-triiodobenzoic acid and 1- $N$-naphthylphthalamic acid on indoleacetic acid transport in carnation cuttings: relationship with rooting. Plant Growth Regul 18:183-190

Gutierrez L, Mongelard G, Floková K, Pacurar DI, Novák O, Staswick P, Kowalczyk M, Pacurar M, Demailly H, Geiss G, Bellini C (2012) Auxin controls Arabidopsis adventitious root initiation by regulating jasmonic acid homeostasis. Plant Cell 24:2515-2527

Hagen G, Guilfoyle TJ (1985) Rapid induction of selective transcription by auxins. Mol Cell Biol 5:1197-1203

Hagen G, Martin G, Li Y, Guilfoyle TJ (1991) Auxin-induced expression of the soybean Gh3 promoter in transgenic tobacco plants. Plant Mol Biol 17:567-579

Haissig BE (1974) Metabolism during adventitious root primordium initiation and development. New Zeal J For Sci 4:324-337

Haissig BE (1986) Metabolic processes in adventitious rooting of cuttings. In: Jackson MB (ed) New root formation in plants and cuttings. Martinus Nijhoff Publishers, Dordrecht, pp 141-189

Hajirezaei MR, Takahata Y, Trethewey RN, Willmitzer L, Sonnewald U (2000) Impact of elevated cytosolic and apoplastic invertase activity on carbon metabolism during potato tuber development. J Exp Bot 51:439-445

Hartig B, Beck E (2006) Crosstalk between auxin, cytokinins, and sugars in the plant cell cycle. Plant Biol 8:389-396

Hartmann HT, Kester DE, Davies FT Jr., Geneve RL (2011) Hartmann and Kester's plant propagation-principles and practices, 8th edn. (Prentice Hall). Upper Saddle River, New Jersey

Hoffmann M, Hentrich M, Pollmann S (2011) Auxin-oxylipin crosstalk: relationship of antagonists. J Integrative Plant Biol 53:429-445

Husen A, Pal M (2007) Metabolic changes during adventitious root primordium development in Tectona grandis Linn. f. (teak) cuttings as affected by age of donor plants and auxin (IBA and NAA) treatment. New Forest 33:309-323

Jager CE, Symons GM, Glancy NE, Reid JB, Ross JJ (2007) Evidence that the mature leaves contribute auxin to the immature tissues of pea (Pisum sativum L.). Planta 226:361-368

Kerr ID, Bennett MJ (2007) New insight into the biochemical mechanisms regulating auxin transport in plants. Biochem $\mathbf{J}$ 401:613-622

Kevers C, Hausman JF, Faivre-Rampant O, Evers D, Gaspar T (1997) Hormonal control of adventitious rooting: progress and questions. Angew Bot 71:71-79

Klopotek Y, George E, Druege U, Klaering HP (2012) Carbon assimilation of petunia cuttings in a non-disturbed rooting environment: response to environmental key factors and adventitious root formation. Sci Hortic 145:118-126 
Kojima K, Ohtake E, Yu Z (2002) Distribution and transport of IAA in tomato plants. Plant Growth Regul 37:249-254

Komaki S, Sugimoto K (2012) Control of plant cell cycle by developmental and environmental cues. Plant Cell Physiol 53:953-964

Koukourikou-Petridou MA, Bangerth F (1997) Effect of changing the endogenous concentration of auxins and cytokinins and the production of ethylene in pea stem cuttings on adventitious root formation. Plant Growth Regul 22:101-108

Kuraishi S, Uematsu S, Yamaki T (1967) Auxin-induced incorporation of proline in mung bean hypocotyls. Plant Cell Physiol 8:527

Lalonde S, Wipf D, Frommer WB (2004) Transport mechanisms for organic forms of carbon and nitrogen between source and sink. Annu Rev Plant Biol 55:341-372

Lee TH, Sugiyama A, OfosuAnim J, Takeno K, Ohno H, Yamaki S (1997) Activation of sucrose-metabolizing enzymes and stimulation of sucrose uptake by auxin and sucrose in eggplant (Solanum melongena L.). J Plant Physiol 150:297-301

Li Y, Wu YH, Hagen G, Guilfoyle T (1999) Expression of the auxininducible $G H 3$ promoter GUS fusion gene as a useful molecular marker for auxin physiology. Plant Cell Physiol 40:675-682

Lindroth AM, Kvarnheden A, von Arnold S (2001) Isolation of a PSTAIRE CDC2 cDNA from Pinus contorta and its expression during adventitious root development. Plant Physiol Biochem 39:107-114

Liu HJ, Reid DM (1992) Auxin and ethylene-stimulated adventitious rooting in relation to tissue sensitivity to auxin and ethylene production in sunflower hypocotyls. J Exp Bot 43:1191-1198

Ljung K, Bhalerao RP, Sandberg G (2001) Sites and homeostatic control of auxin biosynthesis in Arabidopsis during vegetative growth. Plant J 28:465-474

Logemann J, Schell J, Willmitzer L (1987) Improved method for the isolation of RNA from plant-tissues. Anal Biochem 163:16-20

Lohaus G, Moellers C (2000) Phloem transport of amino acids in two Brassica napus $\mathrm{L}$. genotypes and one $B$. carinata genotype in relation to their seed protein content. Planta 211:833-840

Lovell PH, White J (1987) Anatomical changes during adventitious root formation. In: Jackson MB (ed) New root formation in plants and cuttings. Martinus Nijhoff Publishers, Dordrecht, pp 111-140

Ludwig-Müller J (2009) Molecular basis for the role of auxins in adventitious rooting. In: Niemi K, Scagel C (eds) Adventitious root formation of forest trees and horticultural plants-from genes to applications. Research Signpost, Kerala, pp 1-29

Mishra BS, Singh M, Aggrawal P, Laxmi A (2009) Glucose and auxin signaling interaction in controlling Arabidopsis thaliana seedlings root growth and development. PLoS One 4(2):e4502

Morris DA, Arthur ED (1984) Invertase and auxin-induced elongation in internodal aegments of Phaseolus vulgaris. Phytochemistry 23:2163-2167

Morris DA, Kadir G (1972) Pathways of auxin transport in the intact pea seedling (Pisum sativum L.). Planta 107:171-182

Morris DV, Friml J, Zažímalová E (2004) The transport of auxin. In: Davies PJ (ed) Plant hormones. Kluwer Academic Publishers, Dordrecht The Netherlands, pp 437-470

Müller A, Düchting P, Weiler W (2002) A multiplex GC-MS/MS technique for the sensitive and quantitative single-run analysis of acidic phytohormones and related compounds, and its application to Arabidopsis thaliana. Planta 216:55-56

Neuteboom LW, Ng JMY, Kuyper M, Clijdesdale OR, Hooykaas PJJ, van der Zaal BJ (1999) Isolation and characterization of cDNA clones corresponding with mRNAs that accumulate during auxin-induced lateral root formation. Plant Mol Biol 39:273-287

Neves C, Hand P, Amancio S (2006) Patterns of B-type cyclin gene expression during adventitious rooting of micropropagated cork oak. Plant Cell Tiss Org Cult 86:367-374
Nordström AC, Eliasson L (1991) Levels of endogenous indole-3acetic acid and indole-3-acetylaspartic acid during adventitious root formation in pea cuttings. Physiol Plant 82:599-605

Proels RK, Hause B, Berger S, Roitsch T (2003) Novel mode of hormone induction of tandem invertase genes in floral tissues. Plant Mol Biol 52:191-201

Rapaka VK, Bessler B, Schreiner M, Druege U (2005) Interplay between initial carbohydrate availability, current photosynthesis and adventitious root formation in Pelargonium cuttings. Plant Sci 168:1547-1560

Richard C, Lescot M, Inzé D, De Veylder L (2002) Effect of auxin, cytokinin, and sucrose on cell cycle gene expression in Arabidopsis thaliana cell suspension cultures. Plant Cell Tiss Org 69:167-176

Roitsch T, Gonzalez MC (2004) Function and regulation of plant invertases: sweet sensations. Trends Plant Sci 9:606-613

Rolland F, Baena-Gonzales E, Sheen J (2006) Sugar sensing and signaling in plants: conserved and novel mechanisms. Annu Rev Plant Biol 57:675-709

Sairanen I, Novák Pěnčik A, Ikeda Y, Jones B, Sandberg G, Ljung K (2012) Soluble carbohydrates regulate auxin biosynthesis via PIF proteins in Arabidopsis. Plant Cell 24:4907-4916

Sánchez C, Vielba JM, Ferro E, Covelo G, Solé A, Abarca D, de Mier BS, Díaz-Sala C (2007) Two SCARECROW-LIKE genes are induced in response to exogenous auxin in rooting-competent cuttings of distantly related forest species. Tree Physiol 27:1459-1470

Sorin C, Bussell JD, Camus I, Ljung K, Kowalczyk M, Geiss G, McKhann H, Garcion C, Vaucheret H, Sandberg G, Bellini C (2005) Auxin and light control of adventitious rooting in Arabidopsis require ARGONAUTE1. Plant Cell 17:1343-1359

Staswick PE, Serban B, Rowe M, Tiryaki I, Maldonado MT, Maldonado MC, Suza W (2005) Characterization of an Arabidopsis enzyme family that conjugates amino acids to indole-3acetic acid. Plant Cell 17:616-627

Sun JQ, Xu YX, Ye SQ, Jiang HL, Chen Q, Liu F, Zhou WK, Chen R, Li XG, Tietz O, Wu XY, Cohen JD, Palme K, Li CY (2009) Arabidopsis ASA1 is important for jasmonate-mediated regulation of auxin biosynthesis and transport during lateral root formation. Plant Cell 21:1495-1511

Suzuki T, Kohno K (1983) Changes in nitrogen levels and free aminoacids in rooting cuttings of mulberry (Morus alba). Physiol Plant 59:455-460

Sztein AE, Ilic N, Cohen JD, Cooke TJ (2002) Indole-3-acetic acid biosynthesis in isolated axes from germinating bean seeds: the effect of wounding on the biosynthetic pathway. Plant Growth Regul 36:201-207

Thomas P, Lee MM, Schiefelbein J (2003) Molecular identification of proline-rich protein genes induced during root formation in grape (Vitis vinifera L.) stem cuttings. Plant Cell Environ 26:1497-1504

Tobeňa-Santamaria R, Bliek M, Ljung K, Sandberg G, Mol JN, Souer E, Koes R (2002) FLOOZY of petunia is a flavin monooxygenase-like protein required for the specification of leaf and flower architecture. Genes Dev 16:753-763

Tonon G, Kevers C, Gaspar T (2001) Changes in polyamines, auxins and peroxidase activity during in vitro rooting of Fraxinus angustifolia shoots: an auxin-independent rooting model. Tree Physiol 21:655-663

Underwood BA, Jones ML, Clark DG (2009) Petunia biotechnology. In: Gerats T, Strommer J (eds) Petunia: evolutionary, developmental and physiological genetics, 2nd edn. Springer Life Sciences

Urquhart AA, Joy KW (1982) Transport, metabolism, and redistribution of xylem-borne amino acids in developing pea shoots. Plant Physiol 69:1226-1232 
Wang D, Pei K, Fu Y, Sun Z, Li S, Liu H, Tang K, Han B, Tao Y (2007) Genome-wide analysis of the auxin response factors (ARF) gene family in rice (Oryza sativa). Gene 394:13-24

Woodward AW, Bartel B (2005) Auxin: regulation, action, and interaction. Ann Bot 95:707-735

Yun HS, Yoon IS, Kang BG (2002) Rapid repression of vacuolar invertase in mung bean hypocotyl segments and regulation by sucrose, auxin and light. Plant Growth Regul 38:181-189
Zrenner R, Salanoubat M, Willmitzer L, Sonnewald U (1995) Evidence for the crucial role of sucrose synthase for sink strength using transgenic potato plants (Solanum tuberosum L.). Plant J 7:97-107

Zurbriggen MD, Carrillo N, Tognetti V, Melzer M, Peisker M, Hause B, Hajirezaei MR (2009) Chloroplast-generated reactive oxygen species contribute decisively to localized cell death during a plant-microorganism nonhost interaction. Plant J 60:962-973 